\title{
Isolating Conformers to Assess Dynamics of Peptidic Catalysts Using Computationally Designed Macrocyclic Peptides
}

Elizabeth A. Stone $\ddagger^{\ddagger}$ Parisa Hosseinzadeh ${ }^{\ddagger}$, Timothy W. Craven, Michael J. Robertson, Yaodong Han, Sheng-Ying Hsieh, Anthony J. Metrano, David Baker, Scott J. Miller

${ }^{\ddagger}$ These authors contributed equally

\section{Supporting Information}

Table of Contents

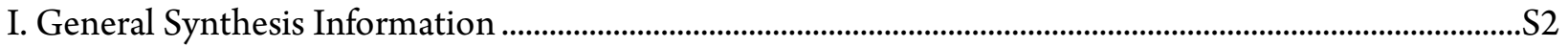

II. Experimental Methods and Characterization.....................................................................................................

III. Solution Structure Data for Cyclic Peptides......................................................................................................

IV. Peptide Catalyzed Atroposelective Quinazolinone Bromination ............................................................S17

V. Computational Methods........................................................................................................................................ S19

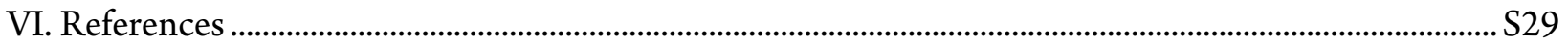




\section{General Synthesis Information}

All reactions were performed under ambient atmosphere unless otherwise noted. Room temperature (rt) is defined as $21-23^{\circ} \mathrm{C}$. Acetonitrile $(\mathrm{MeCN})$, dichloromethane (DCM), Tetrahydrofuran (THF), $N, N$ dimethylformamide (DMF), and toluene (PhMe) were dried over alumina and dispensed under argon from a Glass Contour Seca Solvent Purification System. All reagents were obtained from commercial sources and used without further purification. $N, N$-diisopropyl ethylamine (DIPEA) was distilled over $\mathrm{CaH}$ under a $\mathrm{N}_{2}$ atmosphere prior to use. Deionized water was used for reactions, extraction solutions, and reverse-phase chromatography. All other solvents used for chromatography were HPLC grade.

High-resolution liquid chromatography-mass spectrometry (HRMS) was performed by the Mass Spectrometry Laboratory at the University of Illinois at Urbana-Champaign using a Waters Synapt G2-Si instrument equipped with an electrospray ionization (ESI) detector. For crude data analysis, ultra highperformance liquid chromatography-mass spectrometry (UPLC/MS) was performed with a Waters Acquity UPLC/MS instrument equipped with a reverse-phase BEH C18 column (1.7 mm particle size, $2.1 \times 50 \mathrm{~mm}$ ), a dual atmospheric pressure chemical ionization (API)/electrospray ionization (ESI) mass spectrometry detector, and a photodiode array detector. Flash chromatography was performed using a Biotage Isolera One purification system equipped with a 10, 25, 50, or $100 \mathrm{~g}$ SNAP Ultra (HP Sphere, 25 $\mu \mathrm{m}$ silica) cartridge for normal-phase column chromatography, and 12, 30, 60, or $120 \mathrm{~g}$ SNAP-C18 columns for reverse-phase column chromatography.

Routine ${ }^{1} \mathrm{H}$ NMR spectra were recorded on Agilent 400, 500 or $600 \mathrm{MHz}$ spectrometers at ambient temperature unless otherwise stated. The NMR solvent of chloroform- $d\left(\mathrm{CDCl}_{3}\right)$ was purchased from Cambridge Isotope Laboratories and used without further purification. Spectra were processed using MestReNova 10.0.1 using the automatic phasing and polynomial baseline correction capabilities. Splitting was determined using the automatic multiplet analysis function with intervention as necessary. Spectral data are reported as follows: chemical shift (multiplicity [singlet (s), broad singlet (bs), doublet (d), triplet $(t)$, quartet $(q)$, pentet $(p)$, multiplet $(m)$, doublet of doublets $(\mathrm{dd})$, doublet of doublet of doublets (ddd), doublet of triplet of doublets (dtd), doublet of doublet of doublet of doublets (dddd), doublet of triplets $(\mathrm{dt})$, triplet of doublets $(\mathrm{td})$, complex (comp), etc.], coupling constant ( $\mathrm{Hz})$, integration). Chemical shifts are reported in ppm $(\delta)$, and coupling constants are reported in $\mathrm{Hz} .{ }^{1} \mathrm{H}$ Resonances are referenced to solvent residual peaks for $\mathrm{CDCl}_{3}(7.26 \mathrm{ppm})$. Routine ${ }^{13} \mathrm{C}$ NMR spectra were recorded on Agilent 400, 500 or $600 \mathrm{MHz}$ spectrometers with protons fully decoupled at ambient temperature unless otherwise stated. ${ }^{13} \mathrm{C}$ Resonances are reported in ppm relative to solvent residual peaks for $\mathrm{CDCl}_{3}(77.2$ ppm). 


\section{Experimental Methods and Characterization}

\section{A. Peptide Synthesis}

General Information: The solution phase peptide synthesis of linear and cyclic designs 1-3 was accomplished using the $N$-tert-butoxycarbonyl (Boc) protecting group strategy starting with a commercially available $\mathrm{H}-\mathrm{X}$-OMe $\cdot \mathrm{HCl}$ amino acid as the $C$-terminal residue. Boc-L- $\beta$ Dimethylaminoalanine (Boc-Dmaa-OH) was synthesized from commercially available Boc-L- $\beta$ aminoalanine (Boc-Dap-OH; CAS: 73259-81-1) according to the procedure described by Metrano et al. ${ }^{1}$ A general procedure for each peptide coupling and deprotection step is described below.

Peptide Coupling: To a round bottom flask containing $\mathrm{H}-\mathrm{X}-\mathrm{OMe} \cdot \mathrm{HCl}$ (1.0 equiv) was added Boc-Y$\mathrm{OH}$ ( 1.2 equiv), $\mathrm{HOBt} \cdot \mathrm{H}_{2} \mathrm{O}$ (1.2 equiv), and a magnetic stir bar. The solid mixture was dissolved in dry DCM $(10 \mathrm{~mL}, 0.2 \mathrm{M})$, and EDC. $\mathrm{HCl}$ (1.2 equiv) was then added followed by a slow addition of DIPEA (2.4 equiv). The clear, colorless reaction solution was allowed to stir at $\mathrm{rt}$ for 4-20 h, after which the solution was poured into a separatory funnel, diluted with additional DCM, and washed with $10 \%$ aq. $(\mathrm{w} / \mathrm{v})$ citric acid. The organic layer was separated and subsequently washed with sat. $\mathrm{NaHCO}_{3}(a q)$ and brine. The organics were dried over anhydrous $\mathrm{Na}_{2} \mathrm{SO}_{4}$, filtered, and concentrated in vacuo to provide an off-white foamy solid, which was carried forward without further purification. The identities of the intermediates were confirmed by UPLC/MS.

$N$-Boc Deprotection: The crude Boc-protected peptide was then treated with $4.0 \mathrm{M} \mathrm{HCl}$ in 1,4-dioxane ( 8 equiv). The resulting pale yellow solution was allowed to stir at $\mathrm{rt}$ for $1 \mathrm{~h}$, then the solution was dried azeotropically with DCM to afford a white foam that was carried forward to the next coupling step (see procedure above).

Final Peptide Coupling with Boc-Dmaa-OH: To a flask containing the Boc-deprotected peptide $\cdot \mathrm{HCl}$ (1.0 equiv), Boc-Dmaa-OH (1.2 equiv) was added along with a magnetic stir bar. The solid mixture was dissolved in DCM (0.20 M), and HBTU (1.2) was then added to the stirring solution followed by slow addition of DIPEA (2.4 equiv). The reaction solution was allowed to stir at $\mathrm{rt}$ for 4-20 h, after which the solution was poured into a separatory funnel, diluted with additional DCM, and washed with sat. $\mathrm{NaHCO}_{3}(a q)$ and brine. The organics were dried over anhydrous $\mathrm{Na}_{2} \mathrm{SO}_{4}$, filtered, and concentrated in vacuo.

Procedure for Cyclization: To a 4-dram scintillation vial, $N$-Boc, $C$-OMe protected linear peptide $(0.20$ mmol, 1.0 equiv) was stirred in $\mathrm{HCl}(0.5 \mathrm{~mL}, 4 \mathrm{M}$ in 1,4-dioxanes, 10.0 equiv) at room temperature. Deprotection of the $N$-Boc moiety was monitored using UPLC/MS (typically 1 hour). The solution was then dried azeotropically with DCM. Following drying, the white solid was suspended in a 2:1 (3 mL) mixture of THF and distilled $\mathrm{H}_{2} \mathrm{O}$, then stirred with $\mathrm{LiOH} \cdot \mathrm{H}_{2} \mathrm{O}(33.6 \mathrm{mg}, 0.80 \mathrm{mmol}, 4.0$ equiv). After 5 hours, the reaction was quenched by addition of $\mathrm{HCl}(1 \mathrm{M})$ until the $\mathrm{pH}$ was 4-6. The acidified solution was concentrated in vacuo, then resuspended in DCM $(1.5 \mathrm{~mL})$, DIPEA ( $0.10 \mathrm{~mL}, 0.6 \mathrm{mmol}, 2.8$ equiv), and enough DMF to fully dissolve the peptide $(0.5-2 \mathrm{~mL})$. This solution was added slowly over 8 hours to a $500 \mathrm{~mL}$ round bottom flask containing a mixture of DCM $(200 \mathrm{~mL})$, DIPEA $(0.48 \mathrm{~mL}, 2.7 \mathrm{mmol}$, 13.7 equiv), and HATU ( $1.26 \mathrm{~g}, 3.3 \mathrm{mmol}, 16.5$ equiv) stirring at room temperature. After 12 hours, the 
solution was poured into a separatory funnel and washed with $\mathrm{NaHCO}_{3}(50 \mathrm{~mL})$ and brine $(50 \mathrm{~mL})$. The combined organic layer was dried over $\mathrm{Na}_{2} \mathrm{SO}_{4}$ and concentrated in vacuo. The crude material was purified via reverse-phase column chromatography using a Biotage SP4 system (gradient: 30-100\% $\mathrm{MeOH} / \mathrm{H}_{2} \mathrm{O}$ over $12 \mathrm{CV}$, then $100 \% \mathrm{MeOH} / \mathrm{H}_{2} \mathrm{O}$ over $3 \mathrm{CV}$ ). The desired fractions were pooled and concentrated in vacuo to afford a white or pale yellow solid.

\section{B. Peptide Characterization}

Boc-Dmaa-D-Pro-Acpc-Leu-Pro-Ile-D-Leu-OMe (linear design 1): The crude product was purified using reverse-phase column chromatography (Biotage SNAP Ultra C18 120g, gradient $=30-100 \%$ $\mathrm{MeOH} / \mathrm{H}_{2} \mathrm{O}$ over $12 \mathrm{CV}$, then $100 \% \mathrm{MeOH} / \mathrm{H}_{2} \mathrm{O}$ over $3 \mathrm{CV}$ ). The desired fractions were pooled, concentrated in vacuo, then the residue was subjected to another reverse-phase column (Biotage SNAP Ultra $\mathrm{C} 1860 \mathrm{~g}$, gradient $=30-85 \mathrm{MeCN} / \mathrm{H}_{2} \mathrm{O}$ over $10 \mathrm{CV}$, then $85-100 \% \mathrm{MeCN} / \mathrm{H}_{2} \mathrm{O}$ over $3 \mathrm{CV}$ ) to afford the desired product in $15 \%$ overall yield $(0.267 \mathrm{~g}, 0.30 \mathrm{mmol})$ from H-Leu-OMe $\cdot \mathrm{HCl} .{ }^{1} \mathrm{H}$ NMR $\left(400 \mathrm{MHz}, \mathrm{CDCl}_{3}\right) \delta 7.93(\mathrm{~s}, 1 \mathrm{H}), 7.63(\mathrm{~d}, J=8.3 \mathrm{~Hz}, 1 \mathrm{H}), 7.46-7.30(\mathrm{~m}, 1 \mathrm{H}), 7.12(\mathrm{~s}, 1 \mathrm{H}), 7.06-6.95$ $(\mathrm{m}, 1 \mathrm{H}), 4.84-4.71(\mathrm{~m}, 1 \mathrm{H}), 4.50(\mathrm{p}, J=8.1,6.9 \mathrm{~Hz}, 2 \mathrm{H}), 4.39(\mathrm{dt}, J=17.1,8.4 \mathrm{~Hz}, 1 \mathrm{H}), 4.33-4.22$ $(\mathrm{m}, 1 \mathrm{H}), 3.94-3.81(\mathrm{~m}, 1 \mathrm{H}), 3.68(\mathrm{~s}, 3 \mathrm{H}), 3.63-3.54(\mathrm{~m}, 2 \mathrm{H}), 3.31-3.04(\mathrm{~m}, 1 \mathrm{H}), 2.95-2.51(\mathrm{~m}$, $6 \mathrm{H}), 2.38-2.22(\mathrm{~m}, 1 \mathrm{H}), 2.16(\mathrm{~d}, J=2.6 \mathrm{~Hz}, 1 \mathrm{H}), 2.07-1.93(\mathrm{~m}, 6 \mathrm{H}), 1.86-1.78(\mathrm{~m}, 2 \mathrm{H}), 1.76-1.68$ $(\mathrm{m}, 2 \mathrm{H}), 1.66-1.56(\mathrm{~m}, 6 \mathrm{H}), 1.48-1.42(\mathrm{~m}, 2 \mathrm{H}), 1.42-1.33(\mathrm{~m}, 9 \mathrm{H}), 1.24(\mathrm{~s}, 1 \mathrm{H}), 1.19(\mathrm{~d}, J=6.1 \mathrm{~Hz}$, $1 \mathrm{H}), 1.03(\mathrm{~s}, 2 \mathrm{H}), 0.96-0.83(\mathrm{~m}, 18 \mathrm{H})$. HRMS (ESI) $\mathrm{m} / \mathrm{z}:[\mathrm{M}+\mathrm{H}]^{+}$calcd for $\mathrm{C}_{43} \mathrm{H}_{75} \mathrm{~N}_{8} \mathrm{O}_{10}{ }^{+} 863.5606$, found 863.5600 .

Cyclo-(Dmaa-D-Pro-Acpc-Leu-Pro-Ile-D-Leu-) (design 1): The cyclization was performed on a 0.30 mmol scale from linear design 1 ; $15 \%$ yield $(31.9 \mathrm{mg}, 0.044 \mathrm{mmol}) .{ }^{1} \mathrm{H}$ NMR $\left(600 \mathrm{MHz}, \mathrm{CDCl}_{3}\right) \delta 8.10$ $(\mathrm{d}, J=8.3 \mathrm{~Hz}, 1 \mathrm{H}), 7.74(\mathrm{~s}, 1 \mathrm{H}), 7.29(\mathrm{~d}, J=7.2 \mathrm{~Hz}, 1 \mathrm{H}), 7.26\left(\mathrm{~d}, J\right.$ undetermined $\left.^{*}, 1 \mathrm{H}\right), 5.59(\mathrm{~d}, J=9.8$ $\mathrm{Hz}, 1 \mathrm{H}), 4.54(\mathrm{ddd}, J=10.3,8.2,4.5 \mathrm{~Hz}, 1 \mathrm{H}), 4.49(\mathrm{dd}, J=9.8,2.7 \mathrm{~Hz}, 1 \mathrm{H}), 4.48-4.46(\mathrm{~m}, 1 \mathrm{H}), 4.44(\mathrm{t}$, $J=8.4 \mathrm{~Hz}, 1 \mathrm{H}), 4.37(\mathrm{dd}, J=8.8,3.9 \mathrm{~Hz}, 1 \mathrm{H}), 4.34(\mathrm{td}, J=6.4,5.5,3.3 \mathrm{~Hz}, 1 \mathrm{H}), 4.03$ (ddd, $J=9.5,7.3$, $4.7 \mathrm{~Hz}, 1 \mathrm{H}), 3.77$ (ddd, $J=10.8,7.2,4.0 \mathrm{~Hz}, 1 \mathrm{H}), 3.59$ (qd, $J=9.6,7.1 \mathrm{~Hz}, 2 \mathrm{H}), 2.49-2.41(\mathrm{~m}, 3 \mathrm{H}), 2.37$ $(\mathrm{dd}, J=12.3,5.7 \mathrm{~Hz}, 1 \mathrm{H}), 2.24(\mathrm{~s}, 6 \mathrm{H}), 2.07-1.94(\mathrm{~m}, 7 \mathrm{H}), 1.90-1.83(\mathrm{~m}, 2 \mathrm{H}), 1.81(\mathrm{~d}, J=10.3 \mathrm{~Hz}$, $1 \mathrm{H}), 1.80-1.76(\mathrm{~m}, 1 \mathrm{H}), 1.68-1.62(\mathrm{~m}, 3 \mathrm{H}), 1.38-1.28(\mathrm{~m}, 3 \mathrm{H}), 1.21(\mathrm{ddd}, J=9.9,7.7,4.4 \mathrm{~Hz}, 1 \mathrm{H})$, 1.05 (ddd, $J=9.9,7.6,4.4 \mathrm{~Hz}, 1 \mathrm{H}), 0.97(\mathrm{~d}, J=6.5 \mathrm{~Hz}, 3 \mathrm{H}), 0.95(\mathrm{dd}, J=5.5,3.7 \mathrm{~Hz}, 6 \mathrm{H}), 0.92(\mathrm{~d}, J=6.6$ $\mathrm{Hz}, 3 \mathrm{H}), 0.88$ (d, $J=6.1 \mathrm{~Hz}, 3 \mathrm{H}), 0.83$ (d, $J=6.0 \mathrm{~Hz}, 3 \mathrm{H}) .{ }^{13} \mathrm{C} \mathrm{NMR}\left(151 \mathrm{MHz}, \mathrm{CDCl}_{3}\right) \delta 174.3,174.1$, 173.3, 172.5, 171.6, 171.3, 170.9, 62.7, 61.8, 59.4, 57.7, 51.9, 50.7, 50.2, 48.1, 47.6, 45.8, 40.3, 37.4, 35.3, 35.0, 29.7, 29.5, 25.9, 25.3, 24.9, 24.7, 24.2, 23.5, 23.5, 21.8, 20.8, 16.7, 16.2, 15.9, 12.6. HRMS (ESI) $\mathrm{m} / \mathrm{z}$ : $[\mathrm{M}+\mathrm{H}]^{+}$calcd for $\mathrm{C}_{37} \mathrm{H}_{63} \mathrm{~N}_{8} \mathrm{O}_{7}{ }^{+} 731.4820$, found 731.4829. ( ${ }^{*} J$ value could not be determined due to peak overlap with the solvent)

Boc-Dmaa-D-Pro-Acpc-Leu-D-Pro-D-Ala-Ile-OMe (linear design 2): The crude product was purified using reverse-phase column chromatography (Biotage SNAP Ultra C18 60g, gradient $=30-100 \%$ $\mathrm{MeOH} / \mathrm{H}_{2} \mathrm{O}$ for $12 \mathrm{CV}$, then $100 \% \mathrm{MeOH} / \mathrm{H}_{2} \mathrm{O}$ over $3 \mathrm{CV}$ ) to afford the desired product in $53 \%$ overall yield $(0.502 \mathrm{~g}, 0.61 \mathrm{mmol})$ from H-Ile-OMe $\cdot \mathrm{HCl}$. ${ }^{1} \mathrm{H} \mathrm{NMR}\left(600 \mathrm{MHz}, \mathrm{CDCl}_{3}\right) \delta 7.96(\mathrm{~d}, J=4.9 \mathrm{~Hz}$, $1 \mathrm{H}), 7.66(\mathrm{~d}, J=8.0 \mathrm{~Hz}, 1 \mathrm{H}), 7.59(\mathrm{~s}, 1 \mathrm{H}), 7.23(\mathrm{~d}, J=8.0 \mathrm{~Hz}, 1 \mathrm{H}), 5.95(\mathrm{~d}, J=4.5 \mathrm{~Hz}, 1 \mathrm{H}), 4.46(\mathrm{dd}, J$ $=8.3,5.3 \mathrm{~Hz}, 1 \mathrm{H}), 4.42-4.38(\mathrm{~m}, 1 \mathrm{H}), 4.38-4.35(\mathrm{~m}, 2 \mathrm{H}), 4.34-4.30(\mathrm{~m}, 1 \mathrm{H}), 4.08(\mathrm{dt}, J=9.7,4.9$ $\mathrm{Hz}, 1 \mathrm{H}), 3.89(\mathrm{dq}, J=13.6,6.5 \mathrm{~Hz}, 2 \mathrm{H}), 3.68(\mathrm{~s}, 3 \mathrm{H}), 3.48(\mathrm{dt}, J=10.4,6.9 \mathrm{~Hz}, 1 \mathrm{H}), 2.59-2.52(\mathrm{~m}, 1 \mathrm{H})$, $2.29-2.25(\mathrm{~m}, 6 \mathrm{H}), 2.24-2.17(\mathrm{~m}, 1 \mathrm{H}), 2.08(\mathrm{dq}, J=12.4,6.0 \mathrm{~Hz}, 1 \mathrm{H}), 2.01-1.93(\mathrm{~m}, 5 \mathrm{H}), 1.93-$ 
$1.73(\mathrm{~m}, 4 \mathrm{H}), 1.61(\mathrm{dq}, J=9.6,5.4 \mathrm{~Hz}, 2 \mathrm{H}), 1.50-1.45(\mathrm{~m}, 2 \mathrm{H}), 1.42(\mathrm{~s}, 9 \mathrm{H}), 1.37$ (dd, $J=7.2,3.4 \mathrm{~Hz}$, $3 \mathrm{H}$ ), 1.23 (dddd, $J=22.4,12.2,7.2,3.0 \mathrm{~Hz}, 2 \mathrm{H}), 1.04(\mathrm{td}, J=8.8,8.1,4.7 \mathrm{~Hz}, 1 \mathrm{H}), 0.97$ (d, $J=6.5 \mathrm{~Hz}$, $3 \mathrm{H}), 0.94(\mathrm{~d}, J=6.4 \mathrm{~Hz}, 3 \mathrm{H}), 0.90(\mathrm{~d}, J=6.9 \mathrm{~Hz}, 3 \mathrm{H}), 0.89-0.84(\mathrm{~m}, 5 \mathrm{H}) . \mathrm{HRMS}(\mathrm{ESI}) \mathrm{m} / \mathrm{z}:[\mathrm{M}+\mathrm{H}]^{+}$ calcd for $\mathrm{C}_{40} \mathrm{H}_{69} \mathrm{~N}_{8} \mathrm{O}_{10}{ }^{+} 821.5137$, found 821.5142.

Cyclo-(Dmaa-D-Pro-Acpc-Leu-D-Pro-D-Ala-Ile) (design 2): 33\% yield (46.1 mg, $0.067 \mathrm{mmol}$ ) from linear design 2. ${ }^{1} \mathrm{H}$ NMR $\left(400 \mathrm{MHz}, \mathrm{CDCl}_{3}\right) \delta 8.06(\mathrm{~d}, J=6.1 \mathrm{~Hz}, 1 \mathrm{H}), 7.31(\mathrm{dd}, J=8.5,5.6 \mathrm{~Hz}, 2 \mathrm{H})$, $6.82(\mathrm{~d}, J=7.8 \mathrm{~Hz}, 1 \mathrm{H}), 6.42(\mathrm{~d}, J=8.4 \mathrm{~Hz}, 1 \mathrm{H}), 4.84(\mathrm{q}, J=7.4 \mathrm{~Hz}, 1 \mathrm{H}), 4.59(\mathrm{dd}, J=9.8,5.1 \mathrm{~Hz}, 1 \mathrm{H})$, $4.54-4.41(\mathrm{~m}, 2 \mathrm{H}), 4.36(\mathrm{td}, J=10.3,9.1,4.7 \mathrm{~Hz}, 2 \mathrm{H}), 4.30(\mathrm{dd}, J=8.4,5.3 \mathrm{~Hz}, 1 \mathrm{H}), 3.88(\mathrm{dt}, J=10.2$, $6.6 \mathrm{~Hz}, 1 \mathrm{H}), 3.69-3.50(\mathrm{~m}, 3 \mathrm{H}), 2.82(\mathrm{dd}, J=12.1,8.0 \mathrm{~Hz}, 1 \mathrm{H}), 2.42(\mathrm{dd}, J=12.2,7.0 \mathrm{~Hz}, 1 \mathrm{H}), 2.26(\mathrm{~s}$, $6 \mathrm{H}), 2.22-2.05(\mathrm{~m}, 2 \mathrm{H}), 1.98(\mathrm{dt}, J=8.5,4.8 \mathrm{~Hz}, 4 \mathrm{H}), 1.92-1.80(\mathrm{~m}, 3 \mathrm{H}), 1.67$ (ddd, $J=24.7,13.2$, $6.5 \mathrm{~Hz}, 2 \mathrm{H}), 1.41(\mathrm{~d}, J=7.6 \mathrm{~Hz}, 4 \mathrm{H}), 1.27-1.16(\mathrm{~m}, 2 \mathrm{H}), 1.16-1.05(\mathrm{~m}, 1 \mathrm{H}), 0.96(\mathrm{~d}, J=6.5 \mathrm{~Hz}, 3 \mathrm{H})$, $0.94(\mathrm{~s}, 3 \mathrm{H}), 0.91(\mathrm{~s}, 3 \mathrm{H}), 0.87(\mathrm{~d}, J=7.5 \mathrm{~Hz}, 3 \mathrm{H}), 0.82(\mathrm{dd}, J=11.8,5.1 \mathrm{~Hz}, 2 \mathrm{H}) .{ }^{13} \mathrm{C}$ NMR $(101 \mathrm{MHz}$, $\left.\mathrm{CDCl}_{3}\right) \delta 173.8,173.4,172.7,172.6,171.6,171.1,170.7,61.8,61.7,59.4,58.6,51.01,49.2,49.1$, 48.2, $47.8,45.8,39.2,38.3,34.3,29.6,29.0,25.1,24.8,24.4,23.3,22.5,17.4,16.3,16.3,16.1,11.9$. HRMS (ESI) $\mathrm{m} / \mathrm{z}:[\mathrm{M}+\mathrm{H}]^{+}$calcd for $\mathrm{C}_{34} \mathrm{H}_{57} \mathrm{~N}_{8} \mathrm{O}_{7}{ }^{+} 689.4350$, found 689.4349 .

Boc-Dmaa-D-Pro-Acpc-Leu-Pro-Phe-Val-D-Val-OMe (linear design 3): The crude product was purified using reverse-phase column chromatography (Biotage SNAP Ultra C18 120g, gradient = 30$100 \% \mathrm{MeCN} / \mathrm{H}_{2} \mathrm{O}$ over $12 \mathrm{CV}$, then $100 \% \mathrm{MeCN}$ over $3 \mathrm{CV}$ ). The desired fractions were pooled, concentrated in vacuo, then the residue was subjected to normal-phase column chromatography (Biotage SNAP Ultra $100 \mathrm{~g}$, gradient $=0-10 \% \mathrm{MeOH} / \mathrm{DCM}$ over $10 \mathrm{CV}$, then $10 \% \mathrm{MeOH} / \mathrm{DCM}$ over $5 \mathrm{CV}$ ) to afford the desired product in $58 \%$ overall yield $(0.170 \mathrm{~g}, 0.17 \mathrm{mmol})$ from $\mathrm{H}$-Ile-OMe $\cdot \mathrm{HCl} .{ }^{1} \mathrm{H} \mathrm{NMR}$ $\left(400 \mathrm{MHz}, \mathrm{CDCl}_{3}\right) \delta 8.04(\mathrm{~d}, J=6.0 \mathrm{~Hz}, 1 \mathrm{H}), 7.68(\mathrm{~d}, J=5.0 \mathrm{~Hz}, 1 \mathrm{H}), 7.60(\mathrm{~s}, 1 \mathrm{H}), 7.28-7.20(\mathrm{~m}, 2 \mathrm{H})$, $7.17(\mathrm{dt}, J=9.9,2.7 \mathrm{~Hz}, 4 \mathrm{H}), 6.96(\mathrm{dd}, J=9.1,3.1 \mathrm{~Hz}, 1 \mathrm{H}), 5.88(\mathrm{~s}, 1 \mathrm{H}), 4.65(\mathrm{~d}, J=10.5 \mathrm{~Hz}, 1 \mathrm{H}), 4.38$ (ddd, $J=13.4,8.3,5.1 \mathrm{~Hz}, 3 \mathrm{H}), 4.36-4.21(\mathrm{~m}, 3 \mathrm{H}), 3.97(\mathrm{q}, J=6.7,6.3 \mathrm{~Hz}, 1 \mathrm{H}), 3.76(\mathrm{dd}, J=11.1,5.4$ $\mathrm{Hz}, 1 \mathrm{H}), 3.69(\mathrm{~s}, 3 \mathrm{H}), 3.61(\mathrm{dd}, J=9.7,6.5 \mathrm{~Hz}, 1 \mathrm{H}), 3.39-3.23(\mathrm{~m}, 2 \mathrm{H}), 3.07-2.89(\mathrm{~m}, 1 \mathrm{H}), 2.65-$ $2.56(\mathrm{~m}, 1 \mathrm{H}), 2.50-2.37(\mathrm{~m}, 1 \mathrm{H}), 2.24(\mathrm{~s}, 6 \mathrm{H}), 2.17(\mathrm{dt}, J=12.7,6.5 \mathrm{~Hz}, 2 \mathrm{H}), 2.12-1.94(\mathrm{~m}, 8 \mathrm{H}), 1.82$ $(\mathrm{p}, J=8.4,7.8 \mathrm{~Hz}, 3 \mathrm{H}), 1.73(\mathrm{ddd}, J=22.4,9.0,4.7 \mathrm{~Hz}, 1 \mathrm{H}), 1.36(\mathrm{~s}, 9 \mathrm{H}), 1.17(\mathrm{dt}, J=14.9,4.8 \mathrm{~Hz}, 1 \mathrm{H})$, $0.97-0.89(\mathrm{~m}, 20 \mathrm{H})$. HRMS (ESI) $\mathrm{m} / z$ : $[\mathrm{M}+\mathrm{H}]^{+}$calcd for $\mathrm{C}_{50} \mathrm{H}_{80} \mathrm{~N}_{9} \mathrm{O}_{11}{ }^{+}$982.5977, found 982.5972.

Cyclo-(Dmaa-D-Pro-Acpc-Leu-Pro-Phe-Val-D-Val-) (design 3): 40\% yield (67.5 mg, $0.080 \mathrm{mmol}$ ) from linear design 3. ${ }^{1} \mathrm{H} \mathrm{NMR}\left(600 \mathrm{MHz}, \mathrm{CDCl}_{3}\right) \delta 8.25(\mathrm{~s}, 1 \mathrm{H}), 8.20(\mathrm{~d}, J=8.4 \mathrm{~Hz}, 1 \mathrm{H}), 7.74(\mathrm{~s}, 1 \mathrm{H})$, $7.61(\mathrm{~d}, J=9.3 \mathrm{~Hz}, 1 \mathrm{H}), 7.28-7.24(\mathrm{~m}, 3 \mathrm{H}), 7.20(\mathrm{t}, J=7.3 \mathrm{~Hz}, 1 \mathrm{H}), 7.16-7.12(\mathrm{~m}, 2 \mathrm{H}), 5.99(\mathrm{~d}, J=$ $7.1 \mathrm{~Hz}, 1 \mathrm{H}), 4.48-4.44(\mathrm{~m}, 1 \mathrm{H}), 4.36(\mathrm{dd}, J=8.7,3.8 \mathrm{~Hz}, 1 \mathrm{H}), 4.33-4.28(\mathrm{~m}, 1 \mathrm{H}), 4.27(\mathrm{dd}, J=9.8$, $4.4 \mathrm{~Hz}, 1 \mathrm{H}), 4.17(\mathrm{t}, J=8.8 \mathrm{~Hz}, 1 \mathrm{H}), 4.10-4.04(\mathrm{~m}, 1 \mathrm{H}), 4.02(\mathrm{dq}, J=11.3,6.9,5.8 \mathrm{~Hz}, 1 \mathrm{H}), 3.97-3.92$ $(\mathrm{m}, 1 \mathrm{H}), 3.90(\mathrm{t}, J=7.4 \mathrm{~Hz}, 1 \mathrm{H}), 3.63-3.49(\mathrm{~m}, 3 \mathrm{H}), 3.27(\mathrm{dd}, J=13.7,4.4 \mathrm{~Hz}, 1 \mathrm{H}), 2.53(\mathrm{dd}, J=12.3$, $10.6 \mathrm{~Hz}, 1 \mathrm{H}), 2.32(\mathrm{dd}, J=12.3,4.8 \mathrm{~Hz}, 1 \mathrm{H}), 2.23(\mathrm{~s}, 6 \mathrm{H}), 2.21-2.14(\mathrm{~m}, 1 \mathrm{H}), 2.11-2.01(\mathrm{~m}, 4 \mathrm{H}), 2.01$ - $1.86(\mathrm{~m}, 5 \mathrm{H}), 1.83-1.75(\mathrm{~m}, 3 \mathrm{H}), 1.72(\mathrm{ddd}, J=9.8,7.7,4.6 \mathrm{~Hz}, 1 \mathrm{H}), 1.16(\mathrm{ddd}, J=14.2,10.2,3.5 \mathrm{~Hz}$, $1 \mathrm{H}), 1.04(\mathrm{~d}, J=6.8 \mathrm{~Hz}, 3 \mathrm{H}), 0.99(\mathrm{~d}, J=6.7 \mathrm{~Hz}, 3 \mathrm{H}), 0.94(\mathrm{~d}, J=6.5 \mathrm{~Hz}, 3 \mathrm{H}), 0.89$ (dd, $J=6.4,2.8 \mathrm{~Hz}$, 9H), 0.78 (d, $J=6.7 \mathrm{~Hz}, 2 \mathrm{H}) .{ }^{13} \mathrm{C}$ NMR $\left(151 \mathrm{MHz}, \mathrm{CDCl}_{3}\right) \delta 173.5,173.4,173.1,173.0,172.7,172.5$, $170.8,170.3$, 138.0, 129.3, 128.6, 127.0, 61.8, 61.4, 60.5, 59.2, 58.6, 56.9, 53.5, 50.9, 50.7, 47.8, 47.8, 45.4, 39.3 , 35.3, 34.3, 32.1, 29.5, 29.3, 27.0, 25.3, 24.7, 24.6, 23.3, 21.6, 21.1, 19.7, 19.3, 19.2, 16.2, 16.1. HRMS (ESI) $\mathrm{m} / \mathrm{z}:[\mathrm{M}+\mathrm{H}]^{+}$calcd for $\mathrm{C}_{44} \mathrm{H}_{68} \mathrm{~N}_{9} \mathrm{O}_{8}{ }^{+} 850.5191$, found 850.5187 . 


\section{UPLC/MS Traces of Linear Peptides}

\section{Linear Design 1}

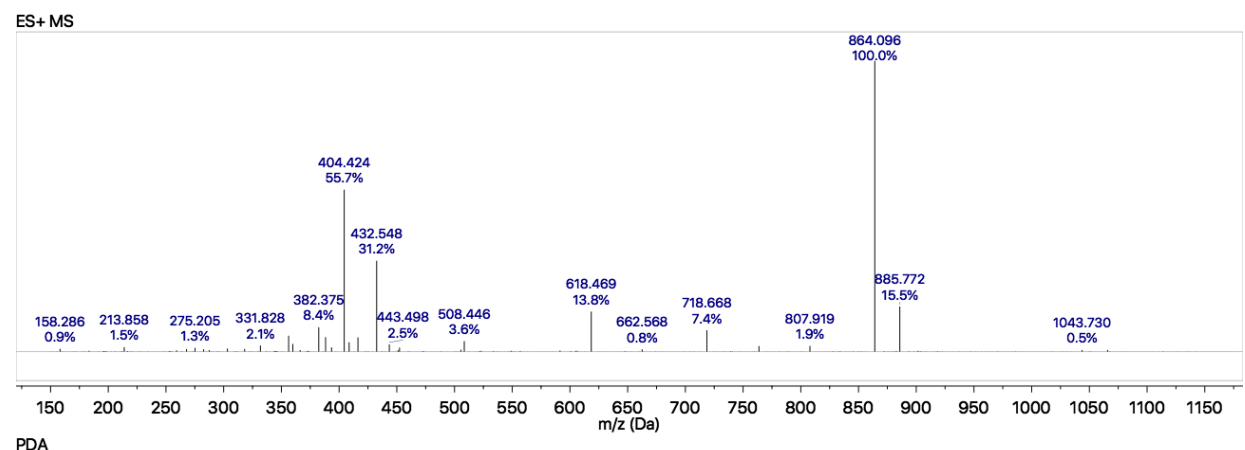

PDA

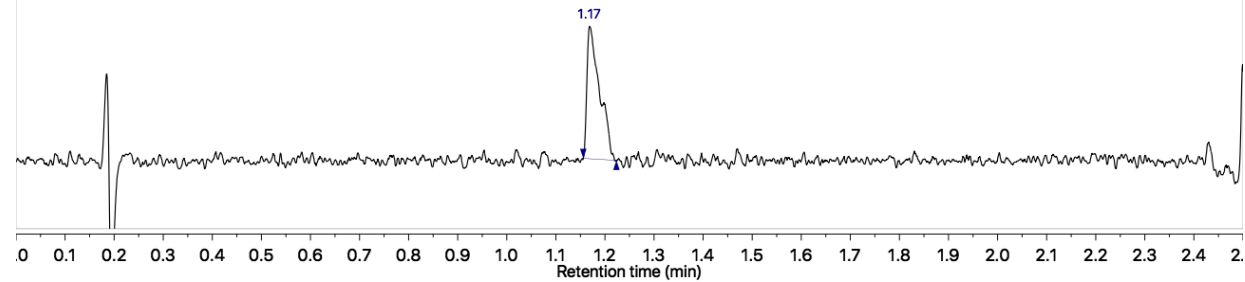

\section{Linear Design 2}

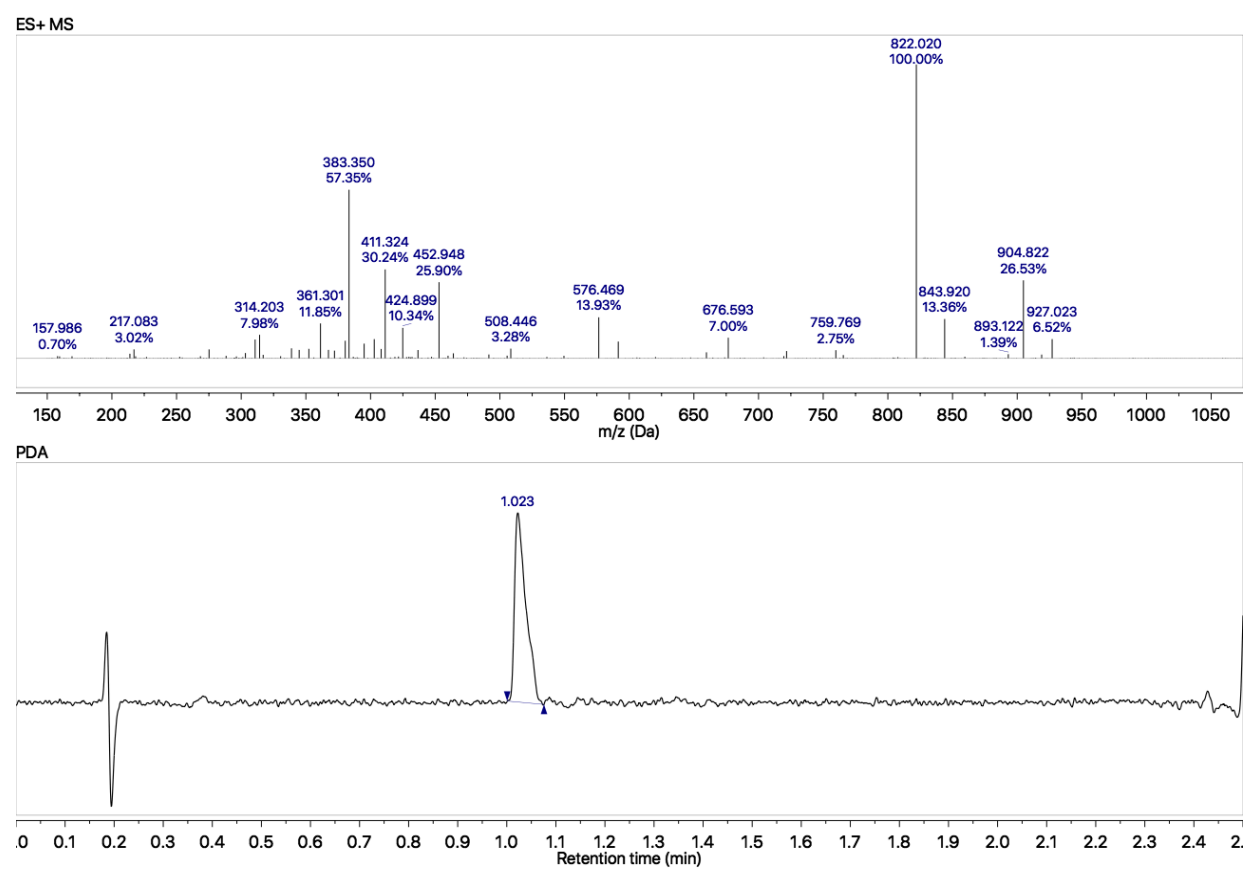




\section{Linear Design 3}

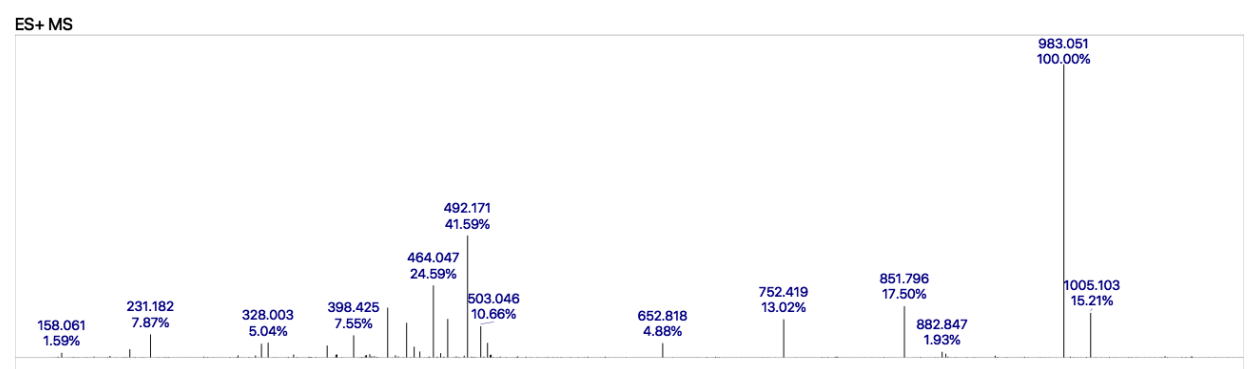

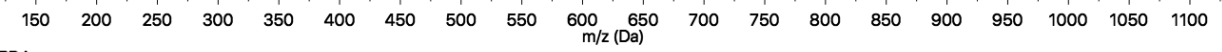
PDA

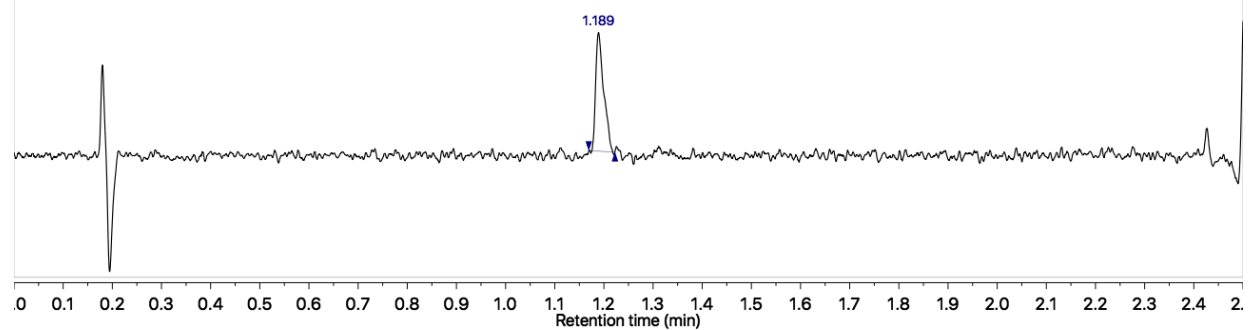

\section{D. ${ }^{1} \mathrm{H}$ NMR Spectra of Linear Peptides}

\section{Linear Design $1,{ }^{1} \mathrm{H}$ NMR (400 $\mathrm{MHz}, \mathrm{CDCl}_{3}$ )}

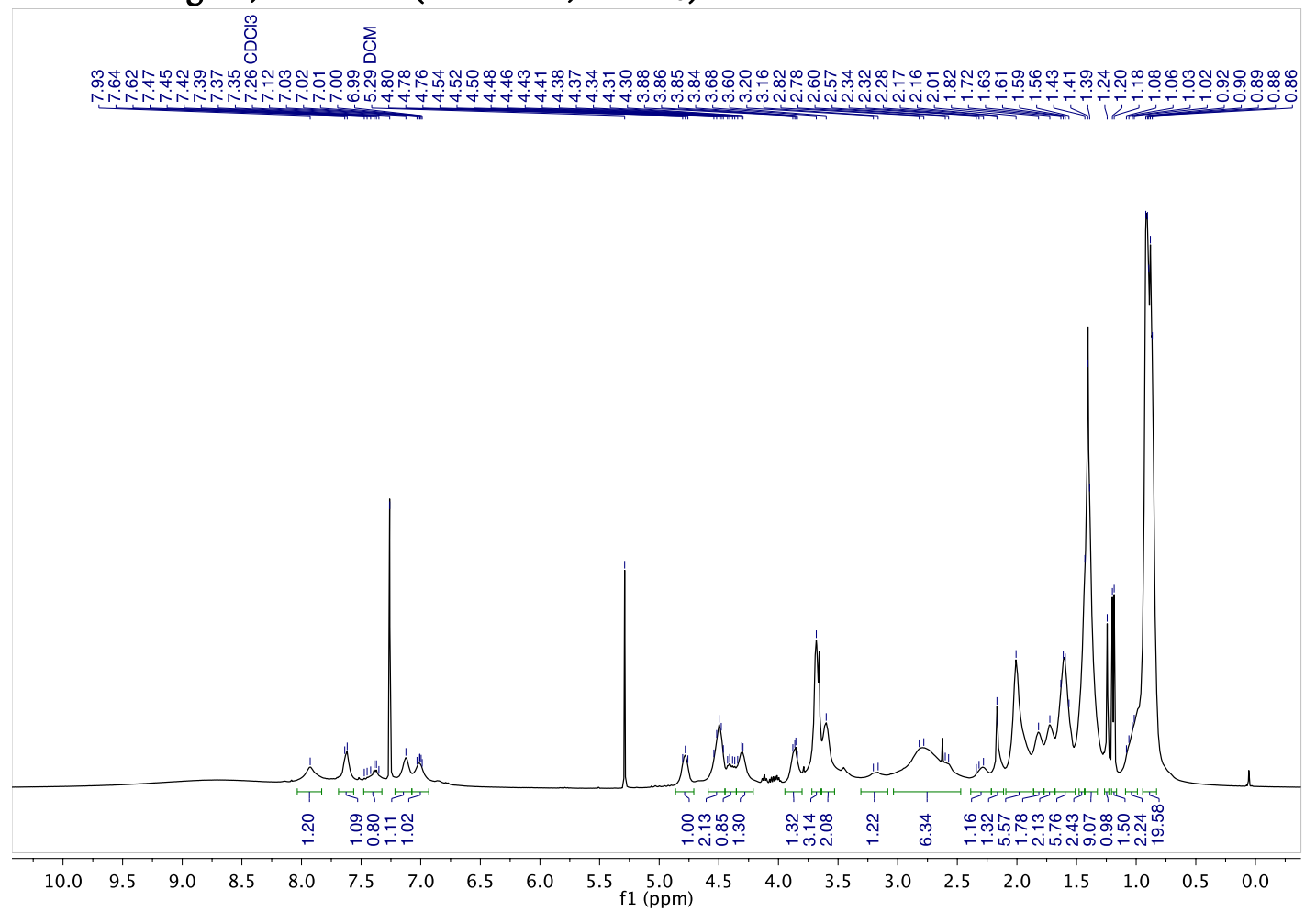




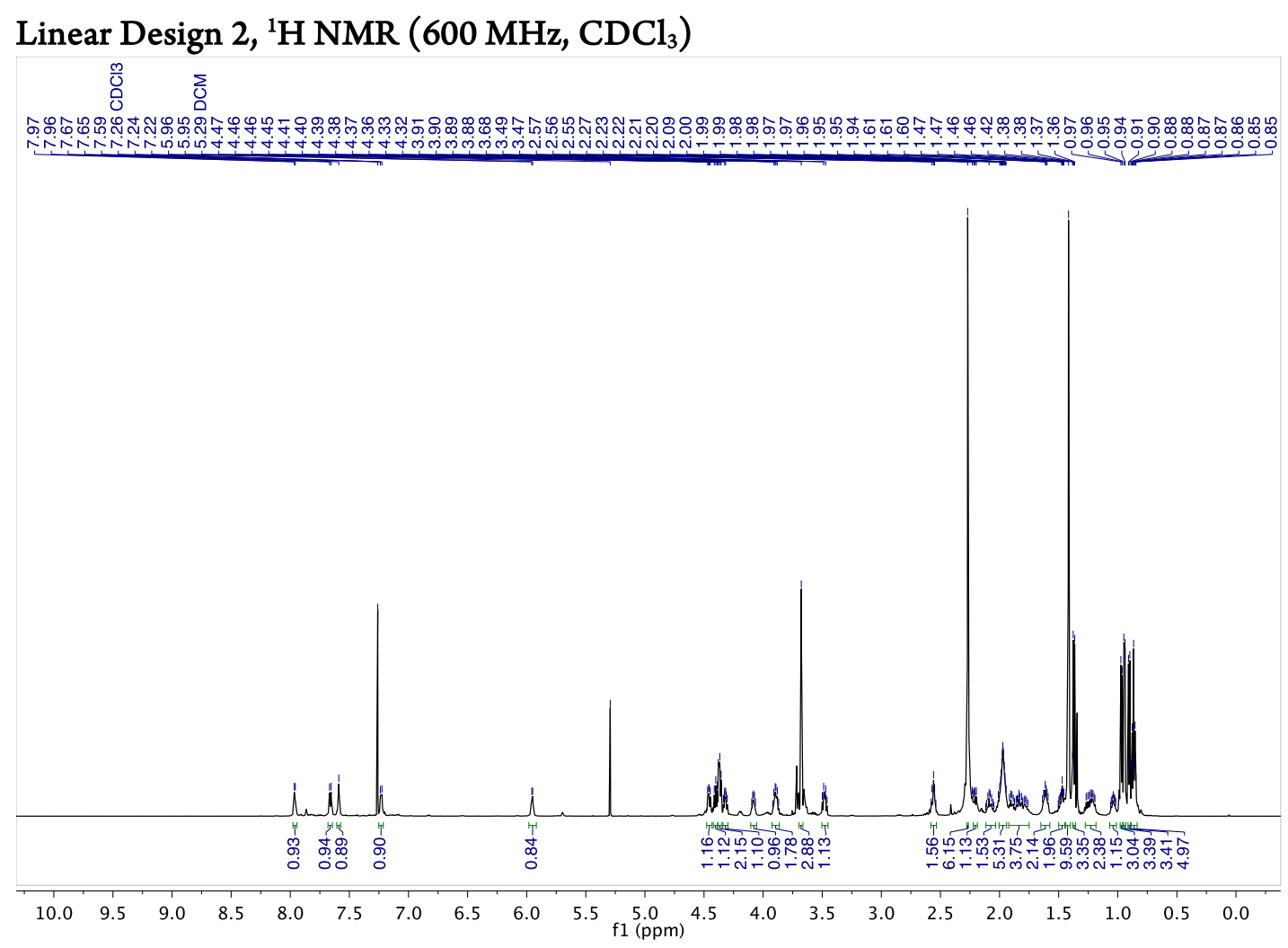

\section{Linear Design 3, ${ }^{1} \mathrm{H}$ NMR (400 MHz, $\mathrm{CDCl}_{3}$ )}

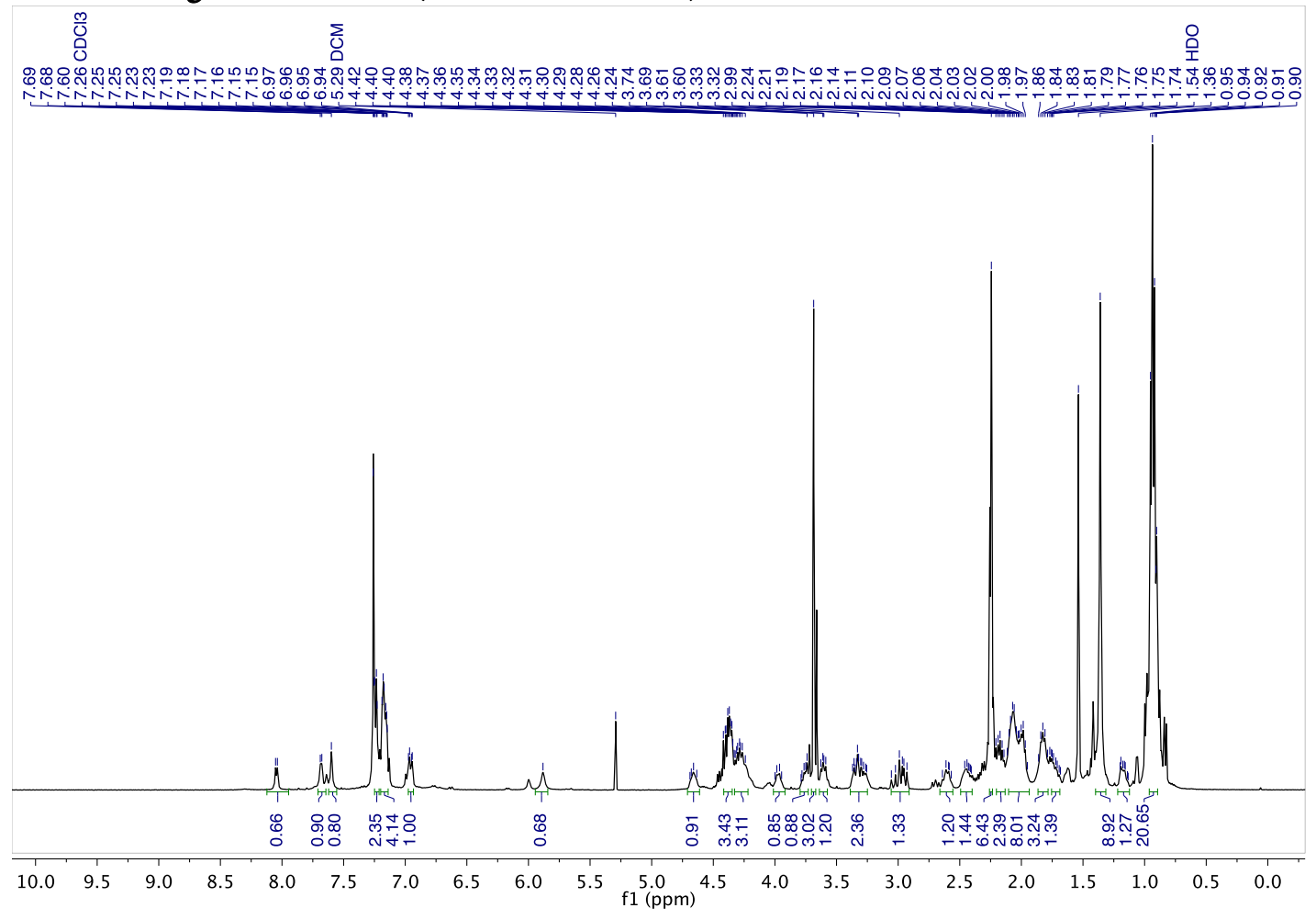




\section{Solution Structure Data for Cyclic Peptides}

\section{A. General Procedure}

NMR studies were performed using peptide dissolved in $\mathrm{CDCl}_{3}(0.001-0.01 \mathrm{M})$, which was demonstrated to be below the aggregation limit for similar peptides. ${ }^{2}$ All data were collected using Agilent 500 or $600 \mathrm{MHz}$ spectrometers at ambient temperature. The NMR solvent, chloroform- $d\left(\mathrm{CDCl}_{3}\right)$ was purchased from Cambridge Isotope Laboratories and used without further purification. ${ }^{1} \mathrm{H}$ Resonances are referenced to solvent residual peaks for $\mathrm{CDCl}_{3}(7.26 \mathrm{ppm}) .{ }^{13} \mathrm{C}$ NMR spectra were recorded on Agilent 400, 500, or $600 \mathrm{MHz}$ spectrometers with protons fully decoupled. ${ }^{13} \mathrm{C}$ Resonances are reported in ppm relative to solvent residual peaks for $\mathrm{CDCl}_{3}(77.2 \mathrm{ppm})$. For solution structure determination, the Varian MLEV17 and NOESY pulse sequences were utilized with $80 \mathrm{~ms}$ and $300 \mathrm{~ms}$ mixing times, respectively.

\section{B. Solution Structure Determination}

The 2D NMR spectra were annotated using the Sparky software package (T. D. Goddard and D. G. Kneller, SPARKY 3, University of California, San Francisco) and the NOE distances from NOESY spectra of design 1 and design 3 were transformed into Rosetta constraint files. The solution structure was then determined using a constraint-based relaxation procedure described by Hosseinzadeh, Bhardwaj, Mulligan, et al. ${ }^{3}$ Each peptide conformation in the generated conformational ensembles for computational folding analysis (see below) was relaxed using a minimal score function with atom-pair constraints. Each conformation was ranked using the described score function. The top-ranking structure is the one that fits the NMR distance constraints best and is energetically reasonable (no clashes between atoms, no unreasonable dihedral angles, etc).

The run command is:

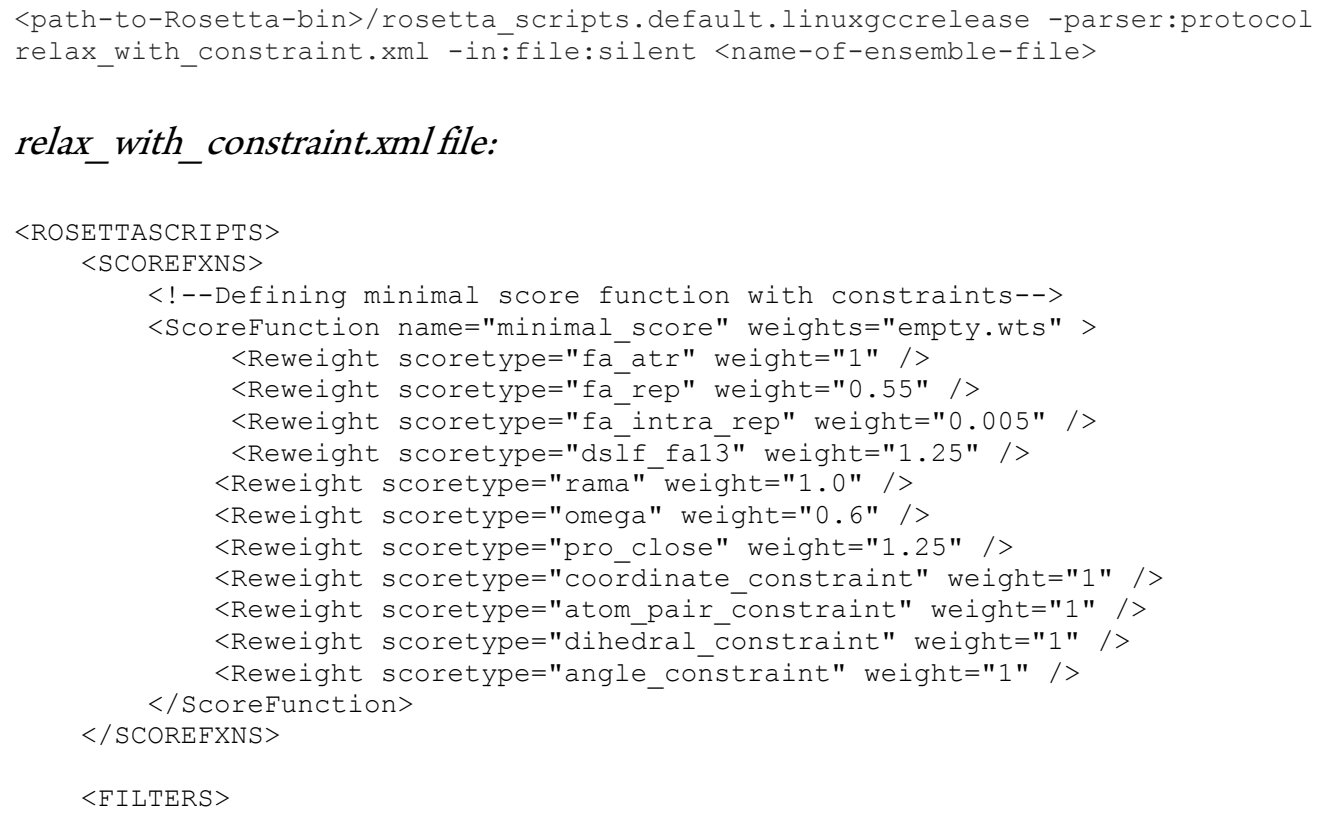




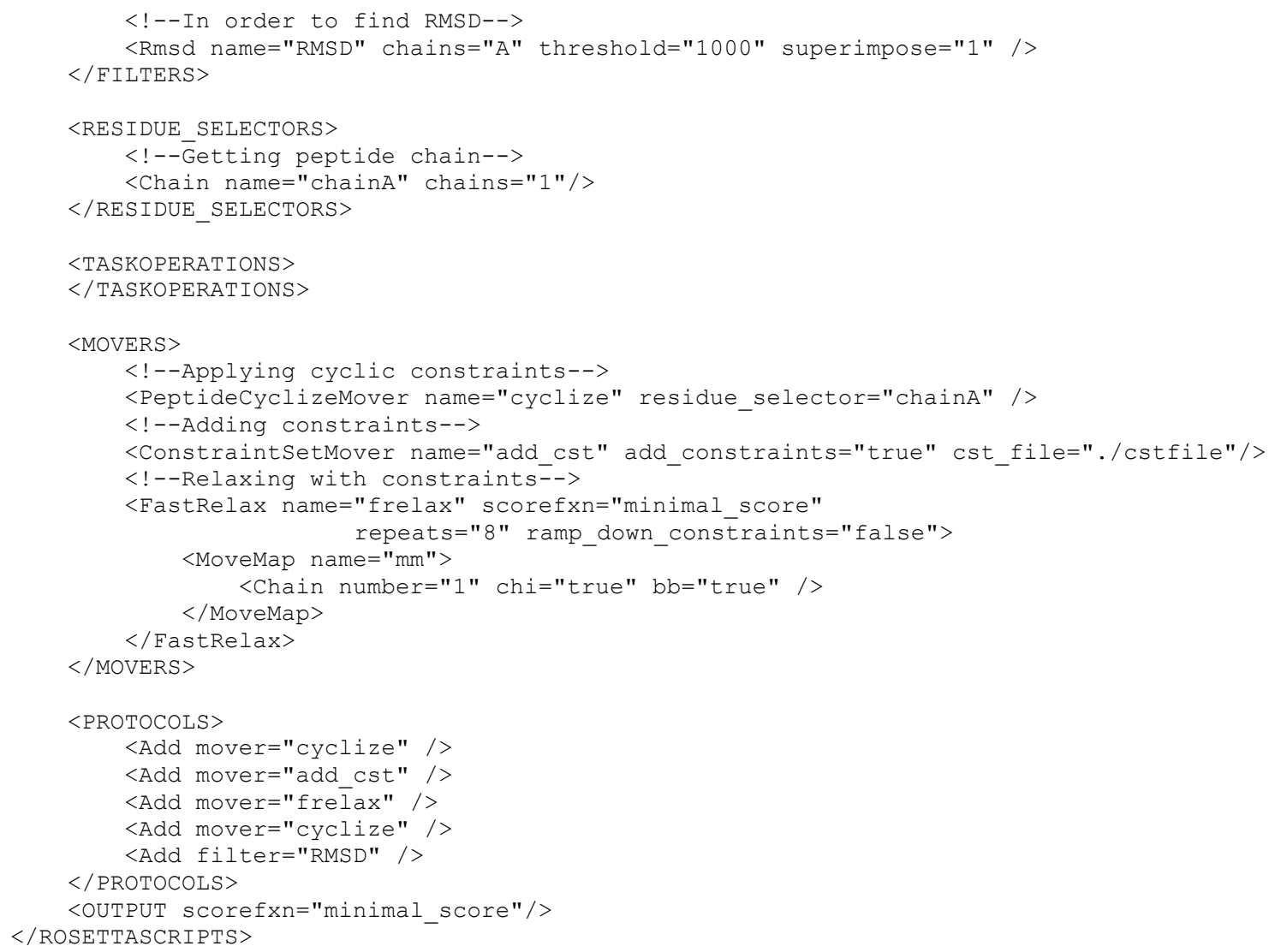

\section{Design 1 Rosetta constraint file (cstfile in the script)}

Atompair N 6 CD1 1 BOUNDED $2.500 \quad 5.500 \quad 0.300$

Atompair N 6 H 2 BOUNDED $2.500 \quad 5.500 \quad 0.300$

AmbiguousConstraint

Atompair N $61 \mathrm{HB} 1$ BOUNDED $2.500 \quad 5.500 \quad 0.300$

Atompair N 6 2HB 1 BOUNDED 2.500 $5.500 \quad 0.300$

END AMBIGUOUS

Atompair H 1 CD 5 BOUNDED $2.500 \quad 5.500 \quad 0.300$

AtomPair H 1 CG 5 BOUNDED $2.500 \quad 5.500 \quad 0.300$

\section{Design 3 Rosetta constraint file (cstfile in the script)}

Atompair N 8 CB 4 BOUNDED 2.500 5.500 0.300

AtomPair N 7 CG 4 BOUNDED 2.500 5.500 0.300

AtomPair N 7 CB 4 BOUNDED 2.500 5.500 0.300

Atompair H 8 H 4 BOUNDED $1.800 \quad 5.000 \quad 0.300$

AmbiguousConstraint

AtomPair N 4 CG1 8 BOUNDED 2.500 $5.500 \quad 0.300$

Atompair N 4 CG2 8 BOUNDED 2.500 $5.500 \quad 0.300$

END AMBIGUOUS

Atompair CB 1 CD1 7 BOUNDED 2.500 5.500 0.300

Atompair CB 1 CD2 7 BOUNDED 2.500 5.500 0.300

Atompair H 3 HA 1 BOUNDED $1.800 \quad 5.000 \quad 0.300$

AmbiguousConstraint

AtomPair CG 4 CD1 6 BOUNDED 2.500 $5.500 \quad 0.300$

Atompair CG 4 CD2 6 BOUNDED $2.500 \quad 5.500 \quad 0.300$

END AMBIGUOUS

Ambiguousconstraint

AtomPair N 3 CD1 1 BOUNDED 2.500 $5.500 \quad 0.300$

Atompair N 3 CD2 1 BOUNDED 2.500 $5.500 \quad 0.300$

END_AMBIGUOUS 
AmbiguousConstraint

AtomPair CG1 8 CD1 6 BOUNDED $2.500 \quad 5.500 \quad 0.300$

AtomPair CG1 8 CD2 6 BOUNDED $2.500 \quad 5.500 \quad 0.300$

AtomPair CG2 8 CD1 6 BOUNDED $2.500 \quad 5.500 \quad 0.300$

AtomPair CG2 8 CD2 6 BOUNDED $2.500 \quad 5.500 \quad 0.300$

END AMBIGUOUS

AmbiguousConstraint

AtomPair CA 6 CG1 8 BOUNDED $2.500 \quad 5.500 \quad 0.300$

Atompair CA 6 CG2 8 BOUNDED $2.500 \quad 5.500 \quad 0.300$

END AMBIGUOUS

\section{Peak Assignments}

Table S1. NMR Chemical Shift Table for Design 1.

\begin{tabular}{|c|c|c|c|c|c|}
\hline Residue & H-N & H- $\boldsymbol{\alpha}$ & H- $\beta$ & H- $\boldsymbol{H}$ & H- $\boldsymbol{~}$ \\
\hline Dmaa & 5.59 & 4.49 & 2.45 & 2.34 \\
\hline D-Pro & & 4.37 & $1.65,1.81$ & & $4.03,3.77$ \\
\hline Acpc & 7.74 & & 1.85 & 1.05 & 02 \\
\hline Leu & 7.29 & 4.47 & 1.97 & 2.06 & 3.59 \\
\hline Pro & & 4.44 & 1.83 & $1.85,0.88$ & 0.83 \\
\hline Ile & 8.10 & 4.54 & $2.01,2.37$ & 1.21 & $0.92,0.97$ \\
\hline D-Leu & 7.26 & 4.34 & & & \\
\hline
\end{tabular}

Table S2. NMR Chemical Shift Table for Design 3.

\begin{tabular}{|c|c|c|c|c|c|c|}
\hline Residue & H-N & H- $\boldsymbol{\alpha}$ & H- $\boldsymbol{\beta}$ & H- $\boldsymbol{\gamma}$ & H- $\boldsymbol{~}$ & Others \\
\hline Dmaa & 7.74 & 4.03 & $2.53,2.24$ & & 2.33 & \\
\hline D-Pro & & 4.36 & $2.10,1.93$ & 2.01 & $3.94,3.53$ & \\
\hline Acpc & 8.25 & & $2.06,1.92$ & & & \\
\hline Leu & 7.27 & 4.31 & $1.72,1.75$ & 1.15 & 0.89 & \\
\hline D-Pro & & 4.08 & 2.32 & 1.71 & $3.59,3.55$ & \\
\hline Phe & 7.15 & 4.27 & $3.60,3.27$ & & 7.26 & $\varepsilon: 7.24, \zeta: 7.15$ \\
\hline Val & 7.61 & 4.47 & 2.06 & $1.04,0.99$ & & \\
\hline D-Val & 8.20 & 4.17 & 2.05 & $0.78,0.95$ & & \\
\end{tabular}




\section{NMR Spectra for Cyclic Peptides}

Design $1,{ }^{1} \mathrm{H}$ NMR (600 MHz, $\mathrm{CDCl}_{3}$ )

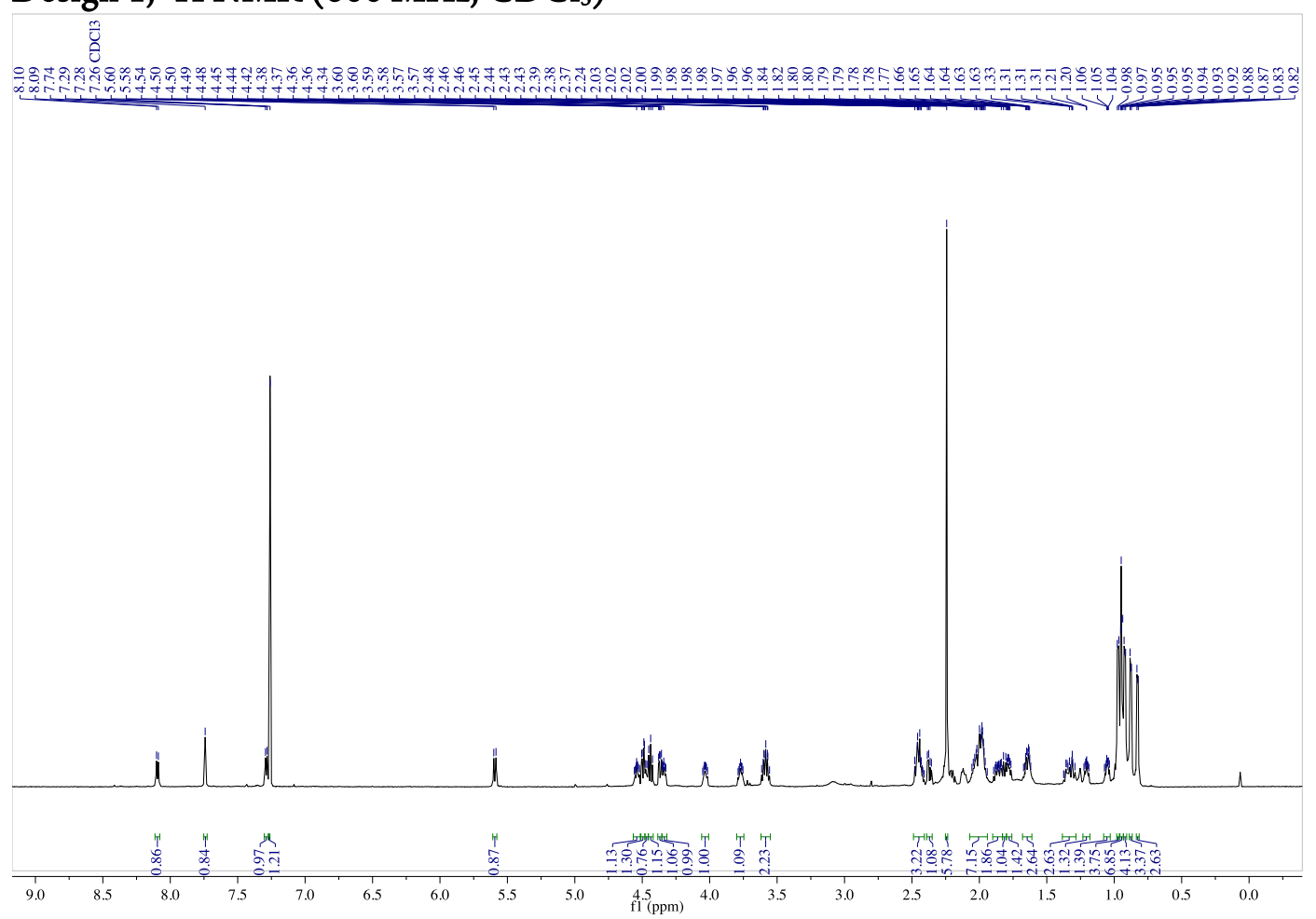

\section{Design $1,{ }^{13} \mathrm{C} \mathrm{NMR}\left(600 \mathrm{MHz}, \mathrm{CDCl}_{3}\right.$ )}

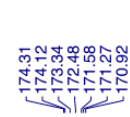

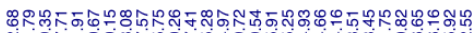

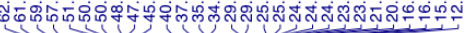

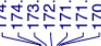

\section{I1}

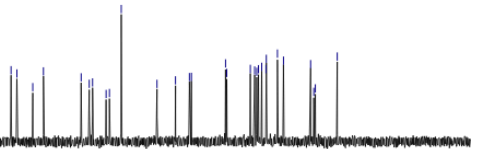

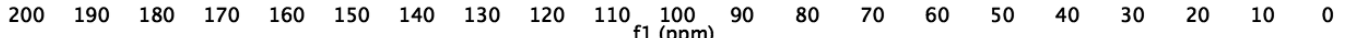


Design 1, COSY NMR (600 MHz, $\left.\mathrm{CDCl}_{3}\right)$

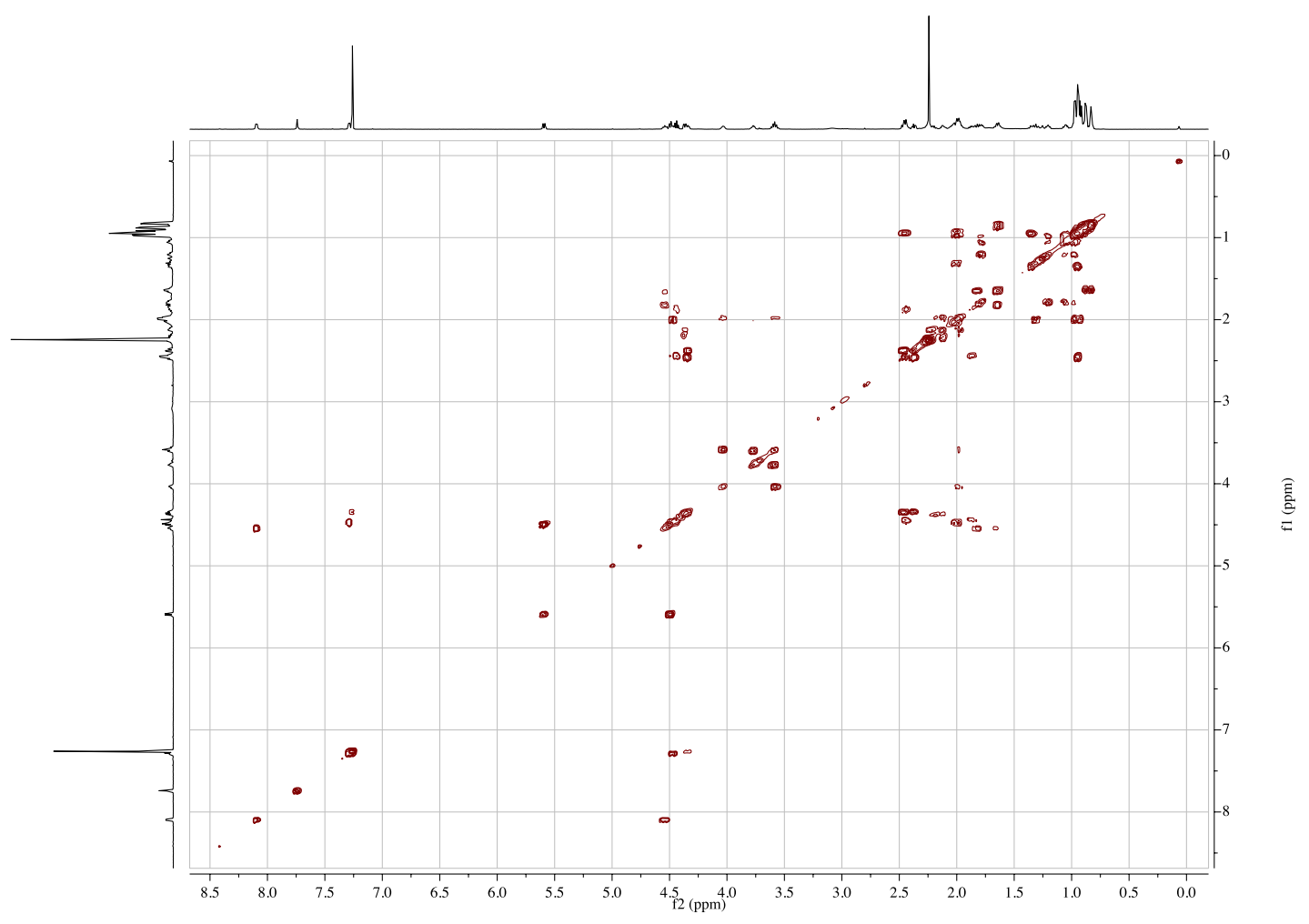

Design 1, NOESY NMR (600 MHz, $\mathrm{CDCl}_{3}$ )

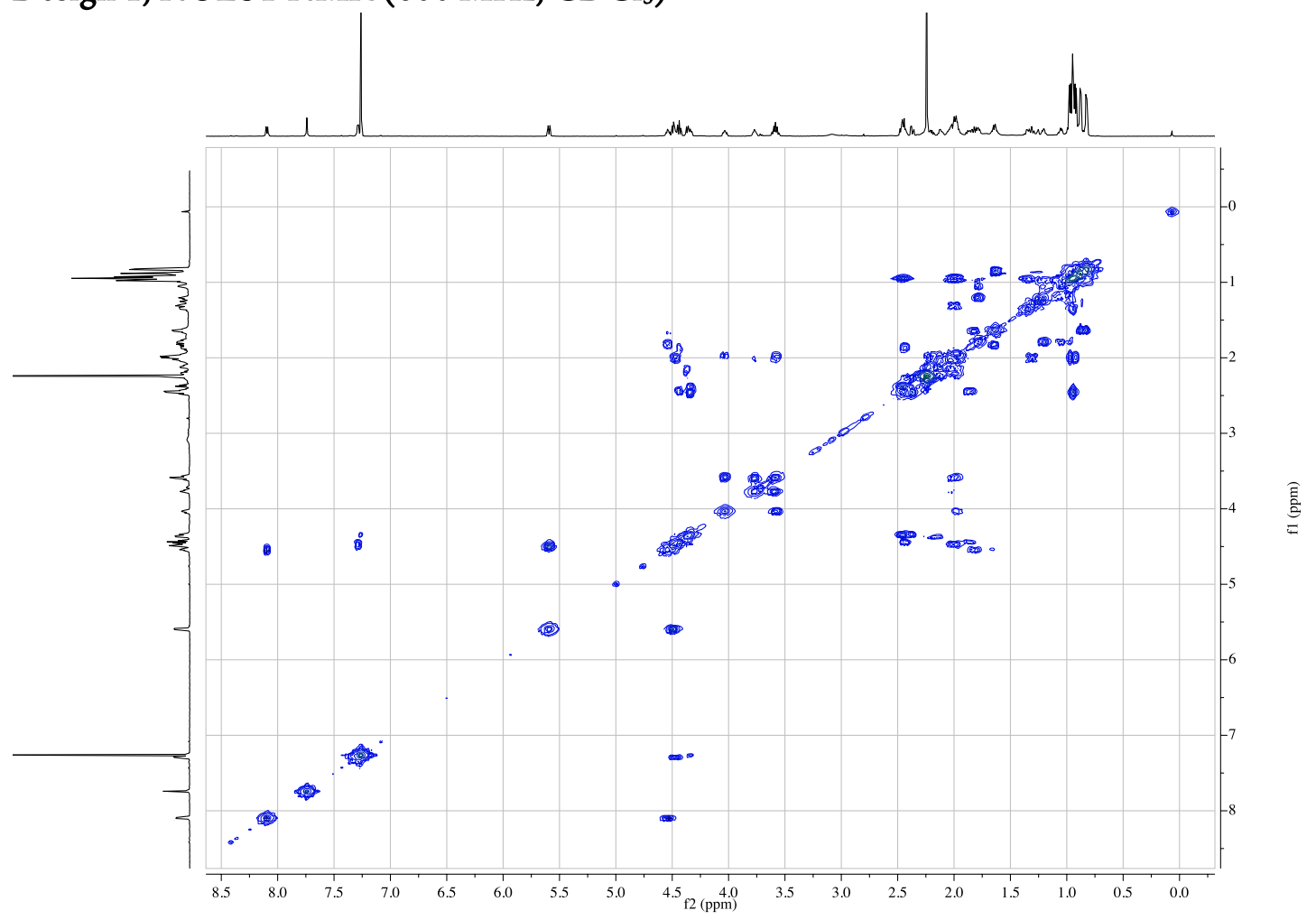




\section{Design 2, ${ }^{1} \mathrm{H}$ NMR (400 $\left.\mathrm{MHz}, \mathrm{CDCl}_{3}\right)$}

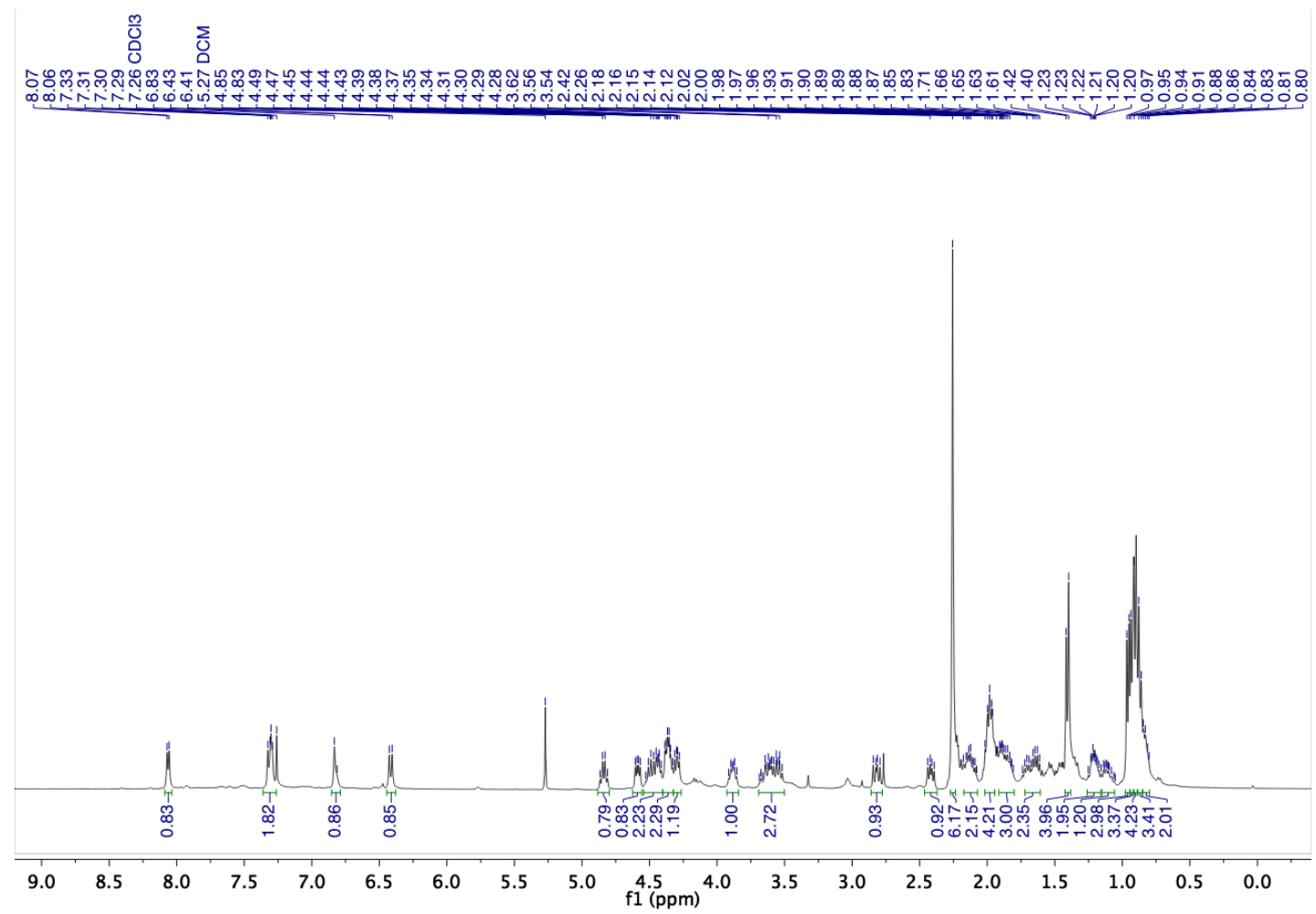

Design $2,{ }^{13} \mathrm{C} \mathrm{NMR}\left(101 \mathrm{MHz}, \mathrm{CDCl}_{3}\right)$
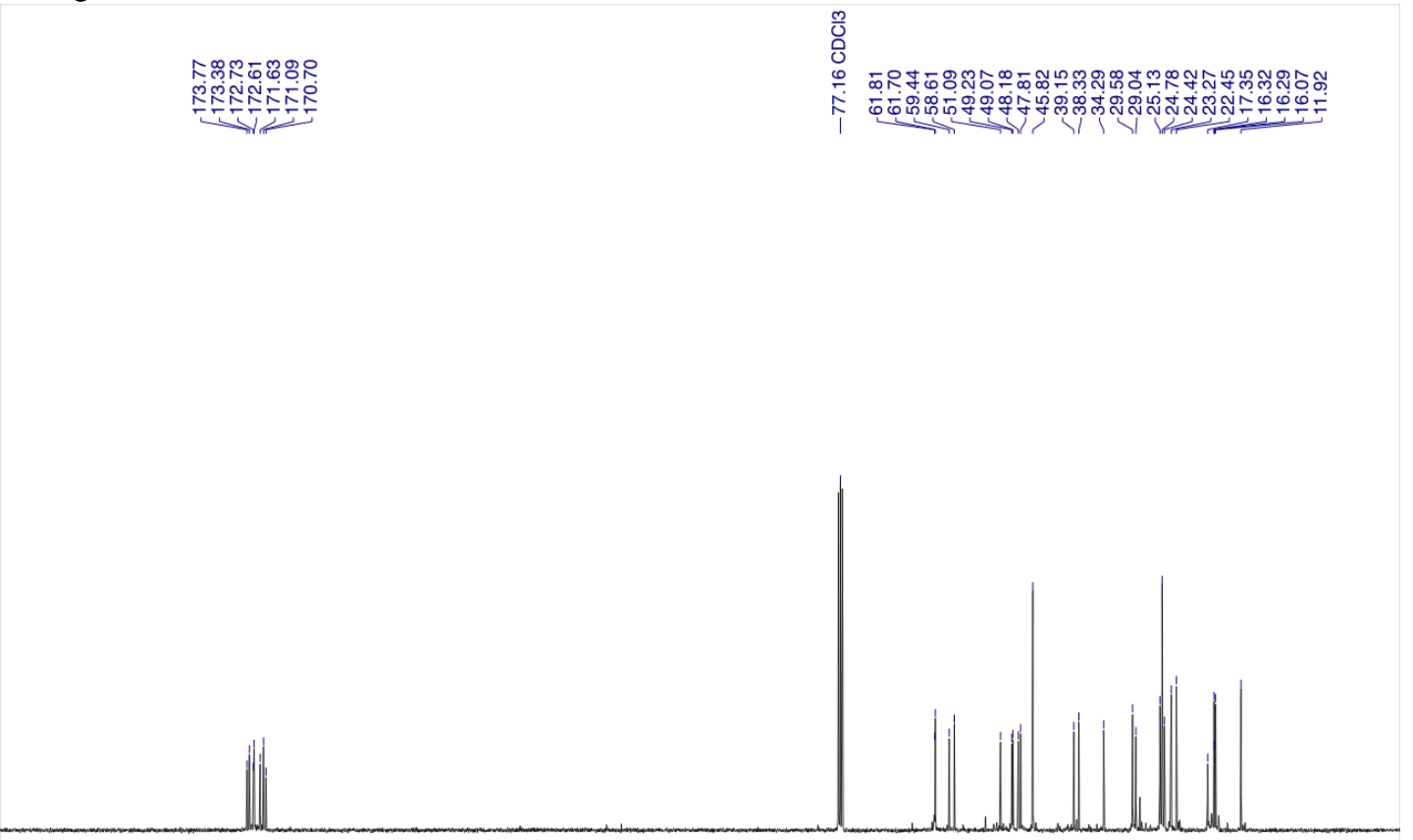

$\begin{array}{lllllllllllllllllllllll}210 & 200 & 190 & 180 & 170 & 160 & 150 & 140 & 130 & 120 & 110 & 100 & 100 & 80 & 70 & 60 & 50 & 40 & 30 & 20 & 10 & 0 & -10\end{array}$ 


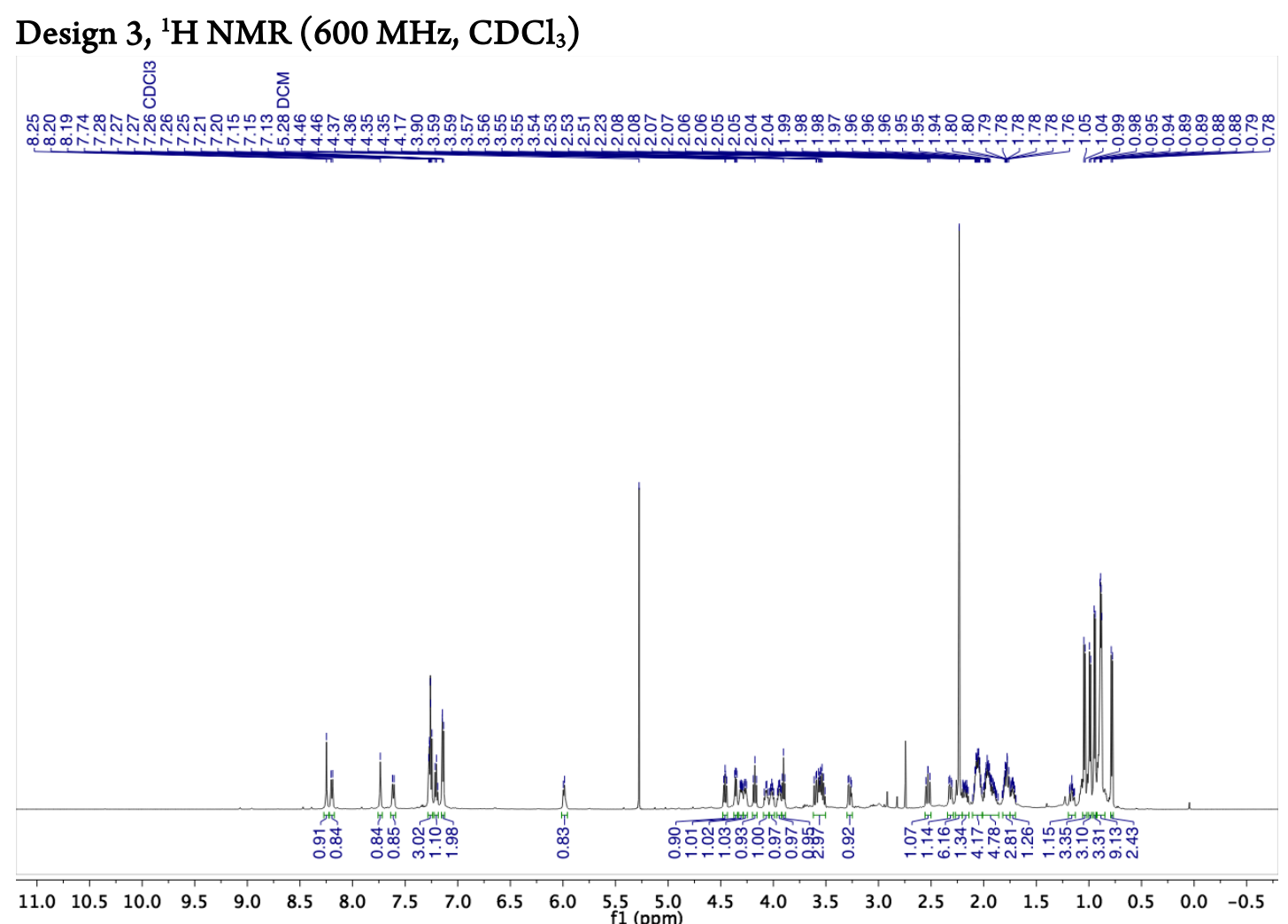

\section{Design 3, ${ }^{13} \mathrm{C}$ NMR (151 $\left.\mathrm{MHz}, \mathrm{CDCl}_{3}\right)$}

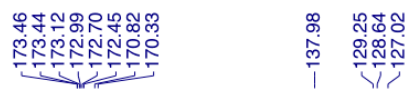

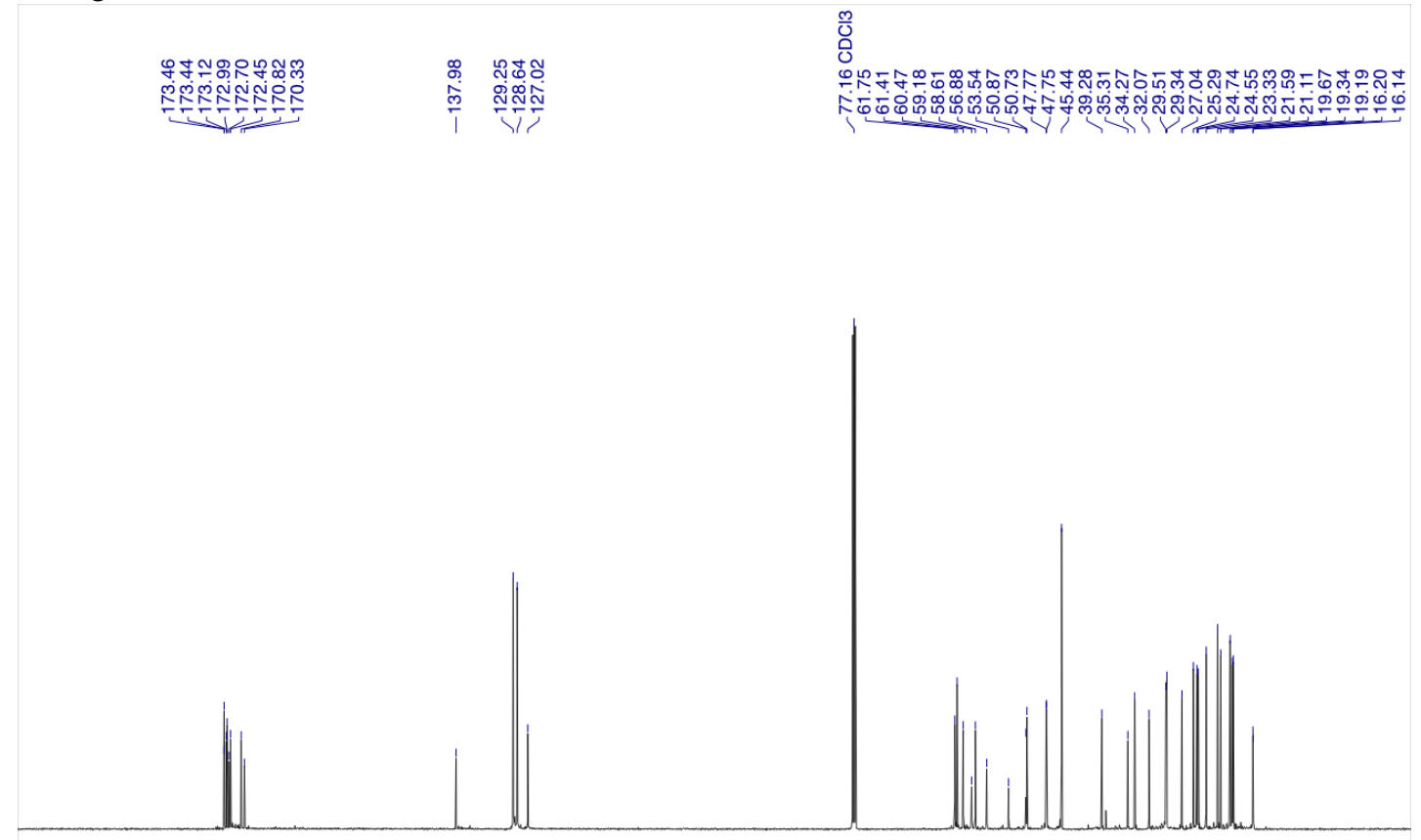

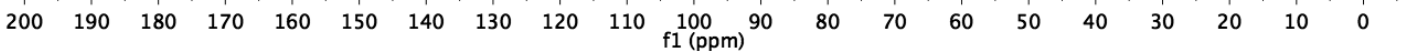




\section{Design 3, COSY NMR (600 MHz, $\left.\mathrm{CDCl}_{3}\right)$}

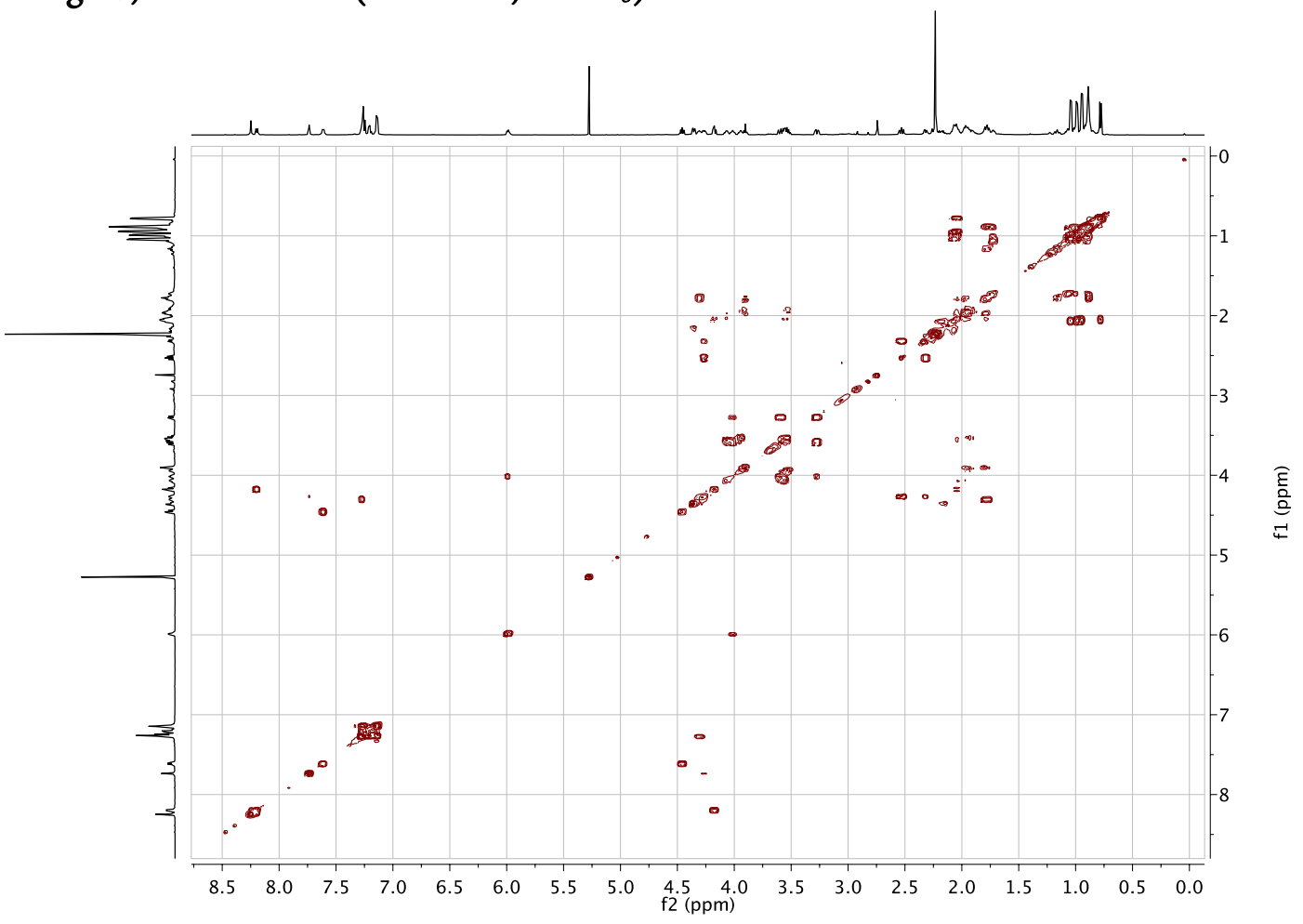

Design 3, NOESY NMR (600 MHz, $\left.\mathrm{CDCl}_{3}\right)$

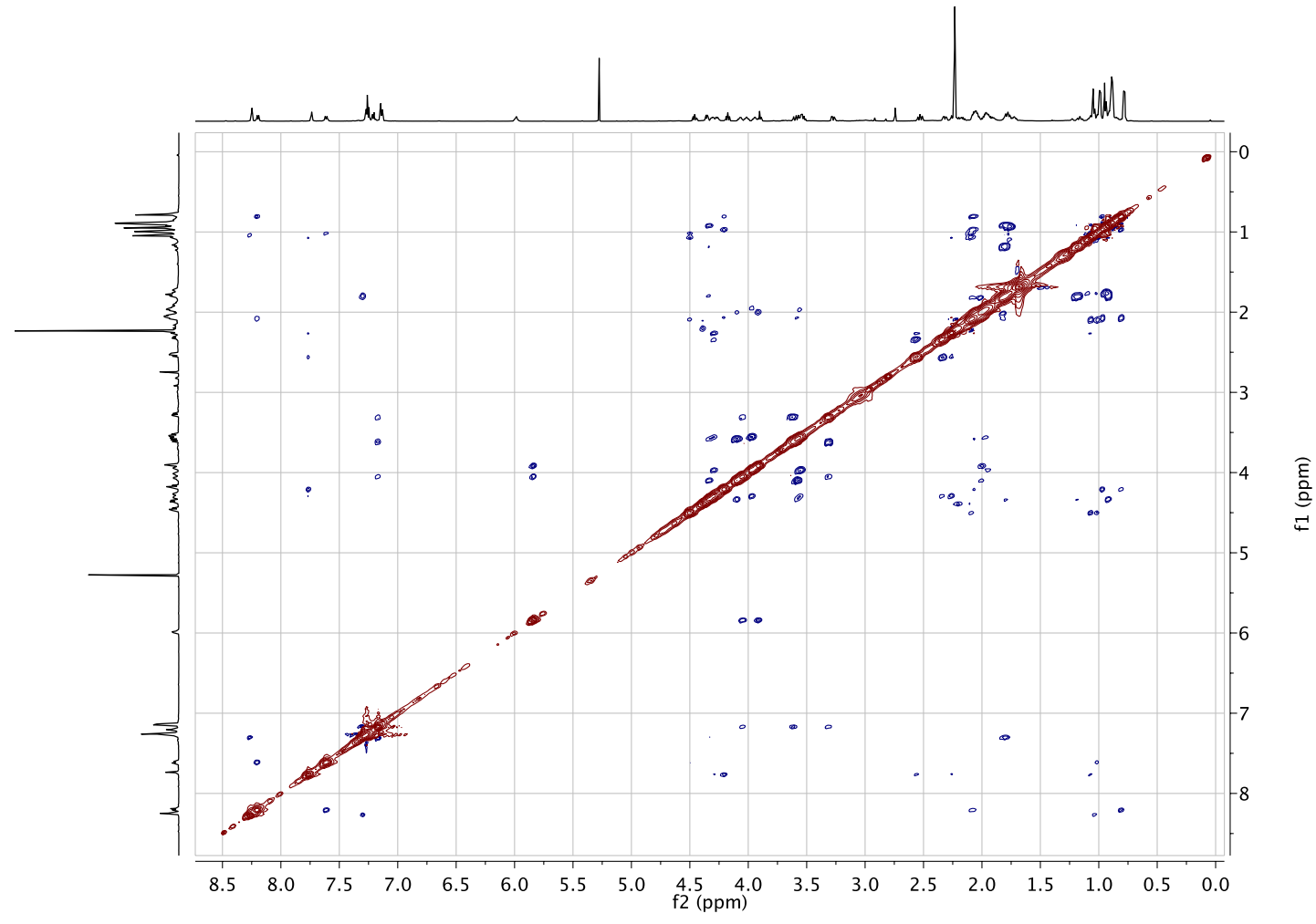




\section{Peptide Catalyzed Atroposelective Quinazolinone Bromination}

\section{A. General Procedure}

This procedure was first reported by Diener et al. ${ }^{4}$ To an oven-dried $20 \mathrm{~mL}$ vial equipped with a magnetic stir bar, 3-(3-hydroxyphenyl)-2-methyl-quinazolin-4(3H)-one (1, $12.6 \mathrm{mg}, 0.050 \mathrm{mmol})$ and peptide catalyst $(0.005 \mathrm{mmol}, 10 \mathrm{~mol} \%)$ were added. The solid mixture was suspended in $5 \mathrm{~mL}$ of $\mathrm{PhMe} / \mathrm{CHCl}_{3}$ $(9: 1 \mathrm{v} / \mathrm{v}, 0.01 \mathrm{M})$, and the resulting suspension was allowed to stir vigorously at room temperature. $\mathrm{N}$ Bromosuccinimide (NBS, $26.7 \mathrm{mg}, 0.15 \mathrm{mmol}, 3.0$ equiv) was added in one aliquot to the stirring solution. The vial was sealed with a cap, and the reaction solution was allowed to stir for 1 hour. The reaction was then quenched by addition of $\mathrm{MeOH}(1 \mathrm{~mL})$ followed by (trimethylsilyl)diazomethane solution (2.0 M in hexanes) until the bright yellow color persisted in solution. The solution was allowed to stir 15-20 minutes at ambient temperature, after which, glacial acetic acid was added dropwise until the solution became clear and colorless. The solvent was removed in vacuo, and the crude reaction mixture was purified by flash chromatography through a pipette silica plug $\left.(1 \times 6 \mathrm{~cm} \mathrm{SiO})_{2}\right)$ washing with EtOAc/hexanes $(1: 1 \mathrm{v} / \mathrm{v})$. The desired fractions were pooled, concentrated in vacuo, and dried thrice azeotropically with dichloromethane. The resulting white foam was dried thoroughly on high vacuum to provide 3-(2,4,6-tribromo-3-methoxyphenyl)-2-methyl-quinazolin-4(3H)-one (2), which was analyzed by chiral HPLC to assess the enantioselectivity of the reaction. Chiral HPLC (Chiralcel OJ-H column, $10 \% \mathrm{EtOH} /$ hexanes eluent, $2 \mathrm{~mL}$ injection, $1 \mathrm{~mL} / \mathrm{min}$ flow rate, regulated at $20^{\circ} \mathrm{C}, 230 \mathrm{~nm}$ ): major enantiomer $t_{R}=9.2 \mathrm{~min}$, minor enantiomer $t_{R}=11.7 \mathrm{~min}$. Conversion was always complete, and thus only er values were tabulated.

Table S3. Enantioselectivity achieved by linear and cyclic peptides in the atroposelective bromination of 1 .

\begin{tabular}{|c|c|c|c|c|}
\hline \multirow{2}{*}{ Peptide* } & \multicolumn{2}{|c|}{ Linear, er } & \multicolumn{2}{c|}{ Cyclic, er } \\
\cline { 2 - 5 } & Trial 1 & Trial 2 & Trial 1 & Trial 2 \\
\hline $\begin{array}{c}\text { Design 1 } \\
\text { Dmaa-D-Pro-Acpc-Leu-Pro-Ile-D-Leu }\end{array}$ & $88: 12$ & $87: 13$ & $76: 24$ & $70: 30$ \\
\hline $\begin{array}{c}\text { Design 2 } \\
\text { Dmaa-D-Pro-Acpc-Leu-D-Pro-D-Ala-Ile }\end{array}$ & $87: 13$ & $90: 10$ & $91: 9$ & $89: 11$ \\
\hline $\begin{array}{c}\text { Design 3 } \\
\text { Dmaa-D-Pro-Acpc-Leu-Pro-Phe-Val-D-Val }\end{array}$ & $89: 11$ & $88: 12$ & $79: 21$ & $76: 24$ \\
\hline
\end{tabular}

*The linear peptides contain a Boc-protecting group on the $N$-terminus and a methyl ester moiety as the $C$-terminus. 


\section{B. Representative HPLC Traces}

\section{Racemic}

MWD1 D, Sig=230,4 Ref=off (AJMIAJM 2017-02-23 11-48-12\1Cl-0301.D)

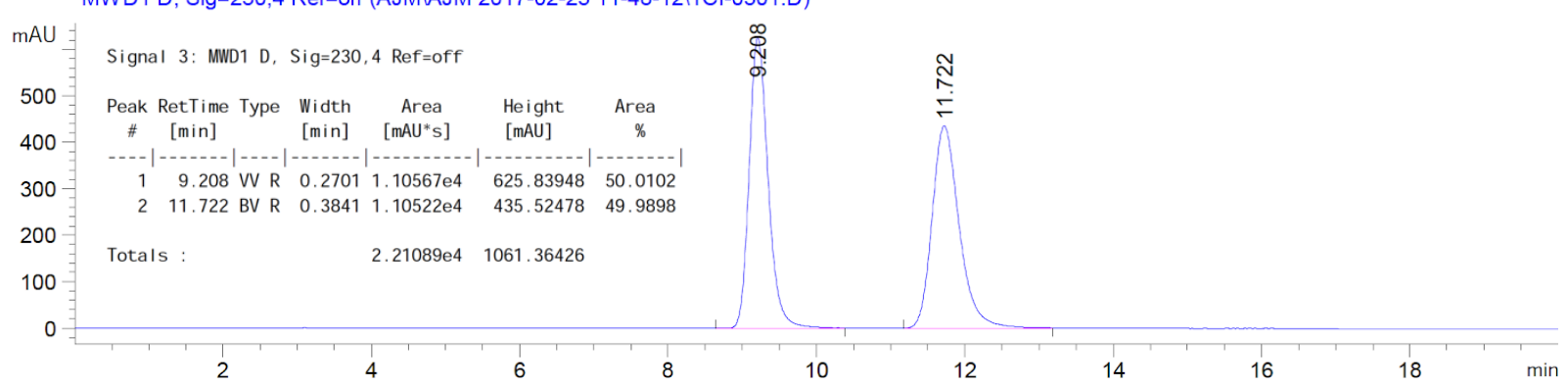

\section{Linear Design 1}

DAD1 B, Sig=230,4 Ref=360,100 (EASIEAS-II-269 2018-12-03 17-49-12l016-0101.D)

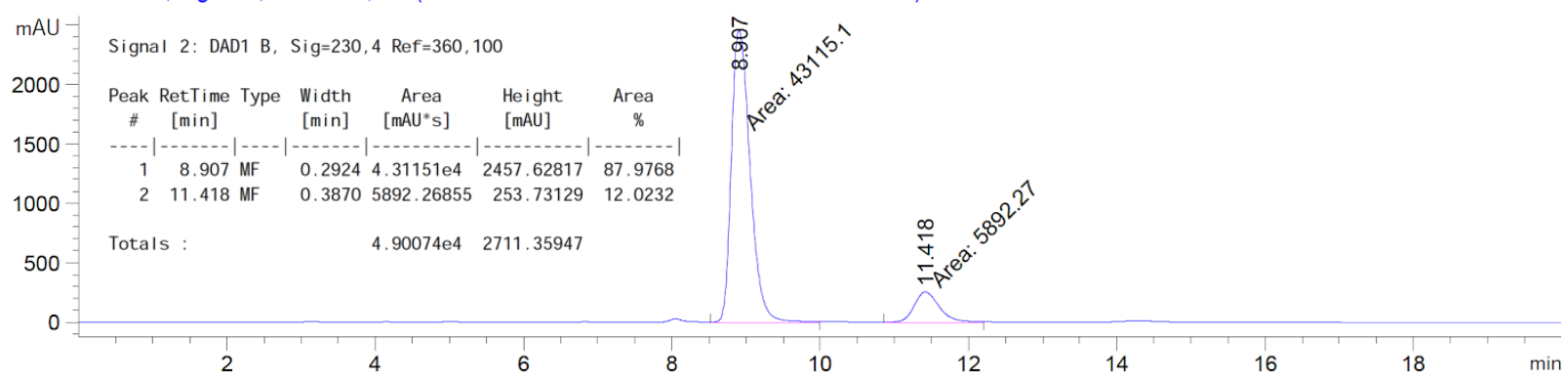

\section{Design 1}

MWD1 D, Sig=230,4 Ref=off (AJMVAJM 2017-02-23 11-48-12\1BH-0101.D)

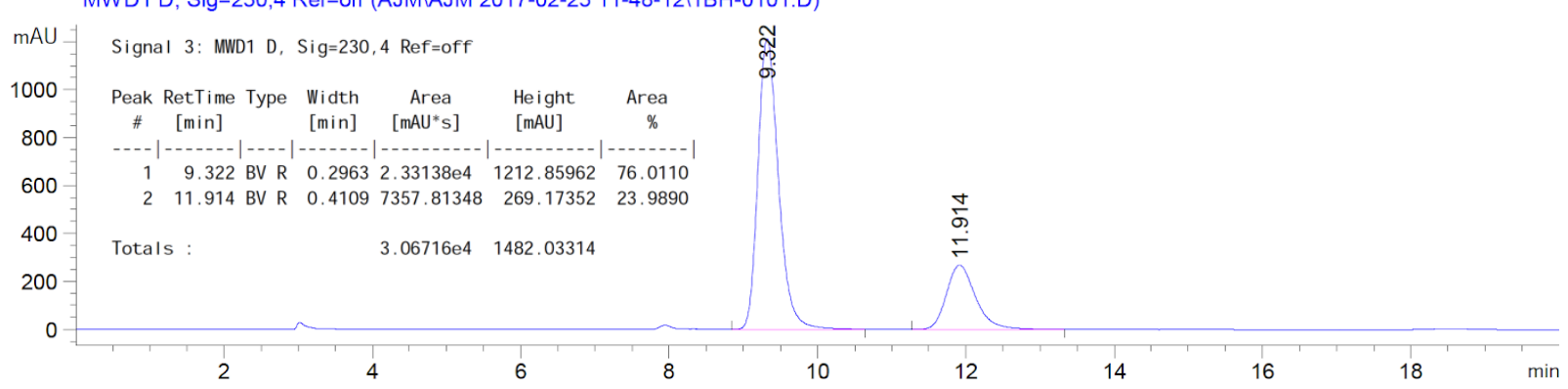

\section{Linear Design 2}

DAD1 B, Sig=230,4 Ref=360,100 (EASIYH-I-26-27 2018-07-18 19-03-061032-0101.D)

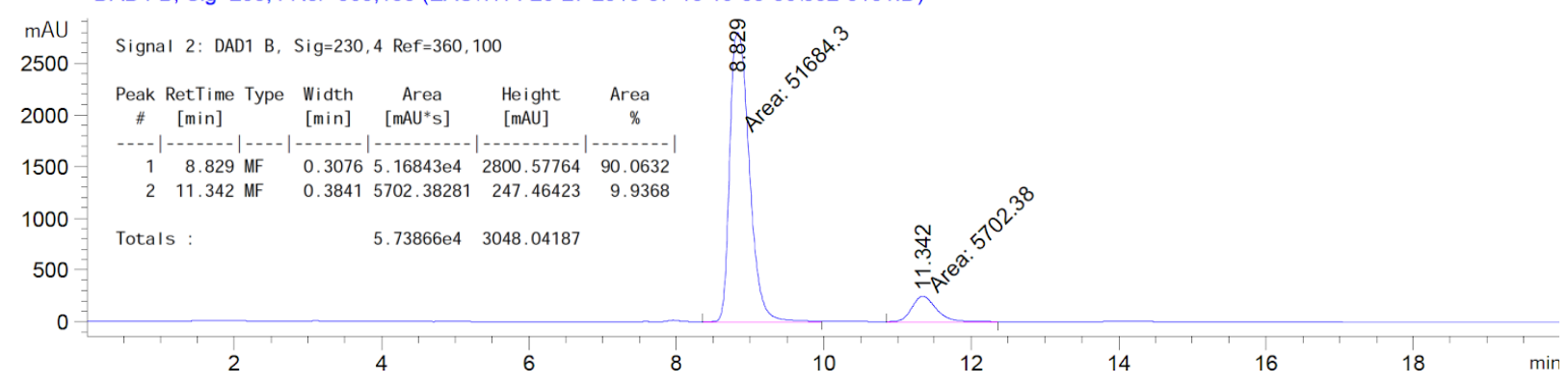




\section{Design 2}

DAD1 B, Sig=230,4 Ref=360,100 (EASIYH-I-26-27 2018-07-18 19-03-061033-0201.D)

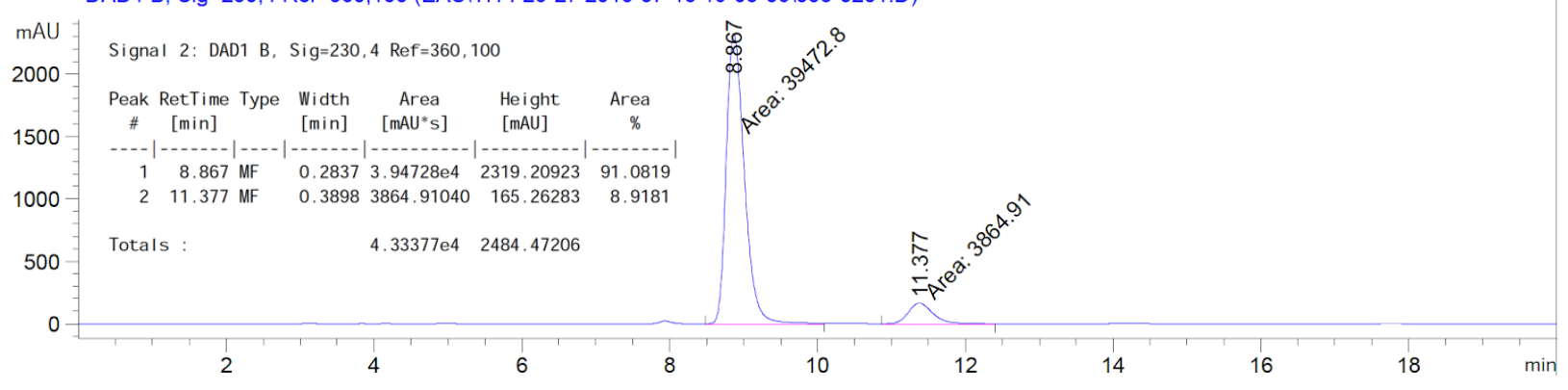

\section{Linear Design 3}

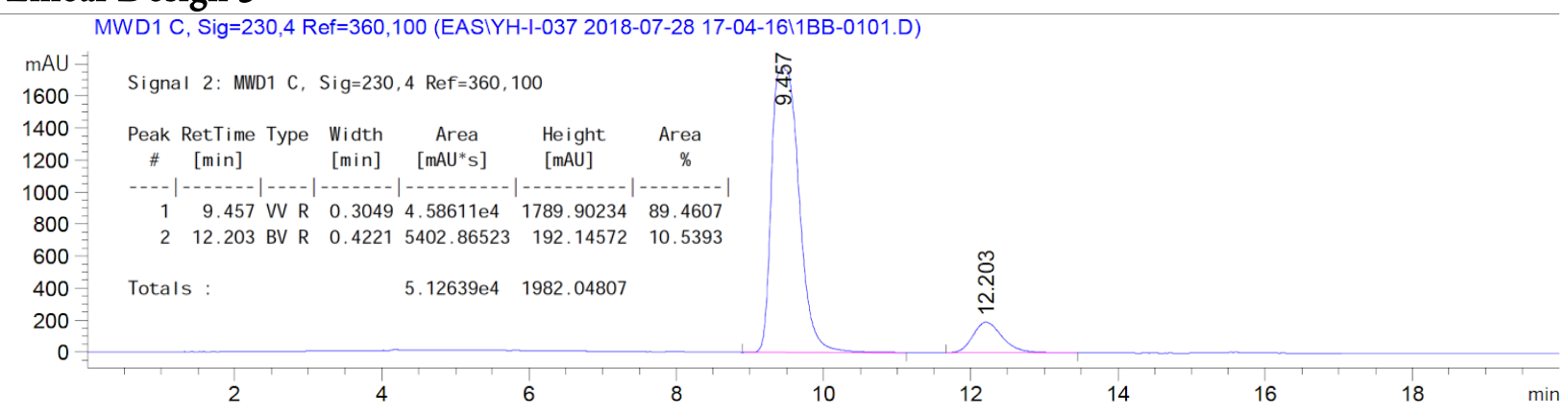

\section{Design 3}

DAD1 B, Sig=230,4 Ref=360,100 (EASIYH-I-38 2018-07-30 18-47-32l031-0101.D)

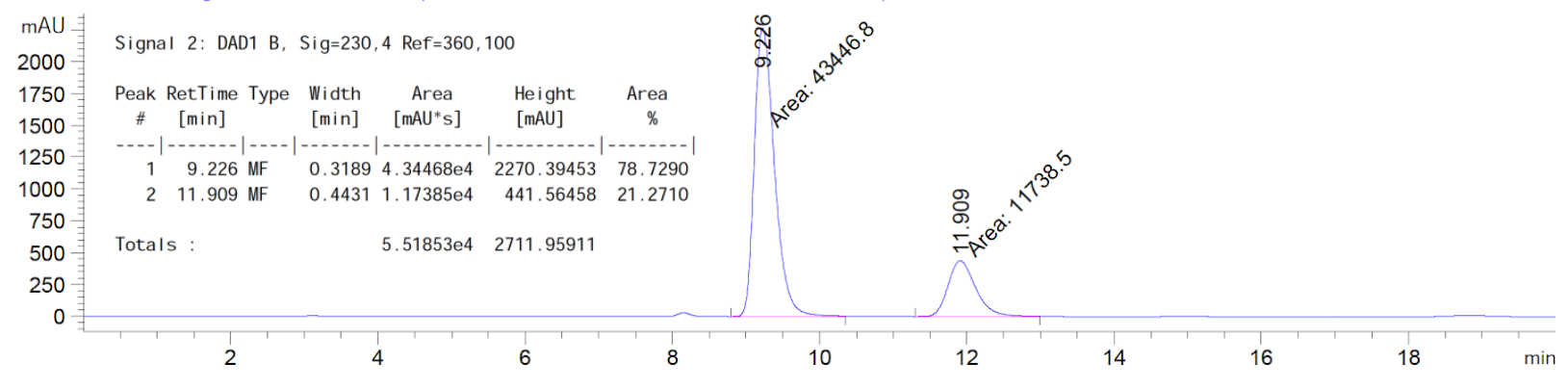

\section{Computational Methods}

\section{A. Generation of Parameter Files and Rotamer Libraries for Dmaa and Acpc Residues}

Rosetta parameter files for Dmaa and Acpc were generated using the protocol reported. ${ }^{5}$ The rotamer library generation for Dmaa was identical to that previously reported. ${ }^{6}$ The protocol for Ramachandran table generation for Acpc was identical to that previously reported. ${ }^{7}$ The rotamer files for Dmaa (DMA.rotlib) and Ramachandran tables for Acpc (ACP_general.rama, ACP_prepro.rama) are provided in Supplemental Rosetta Files (ZIP). 


\section{i. Dmaa Parameters File}

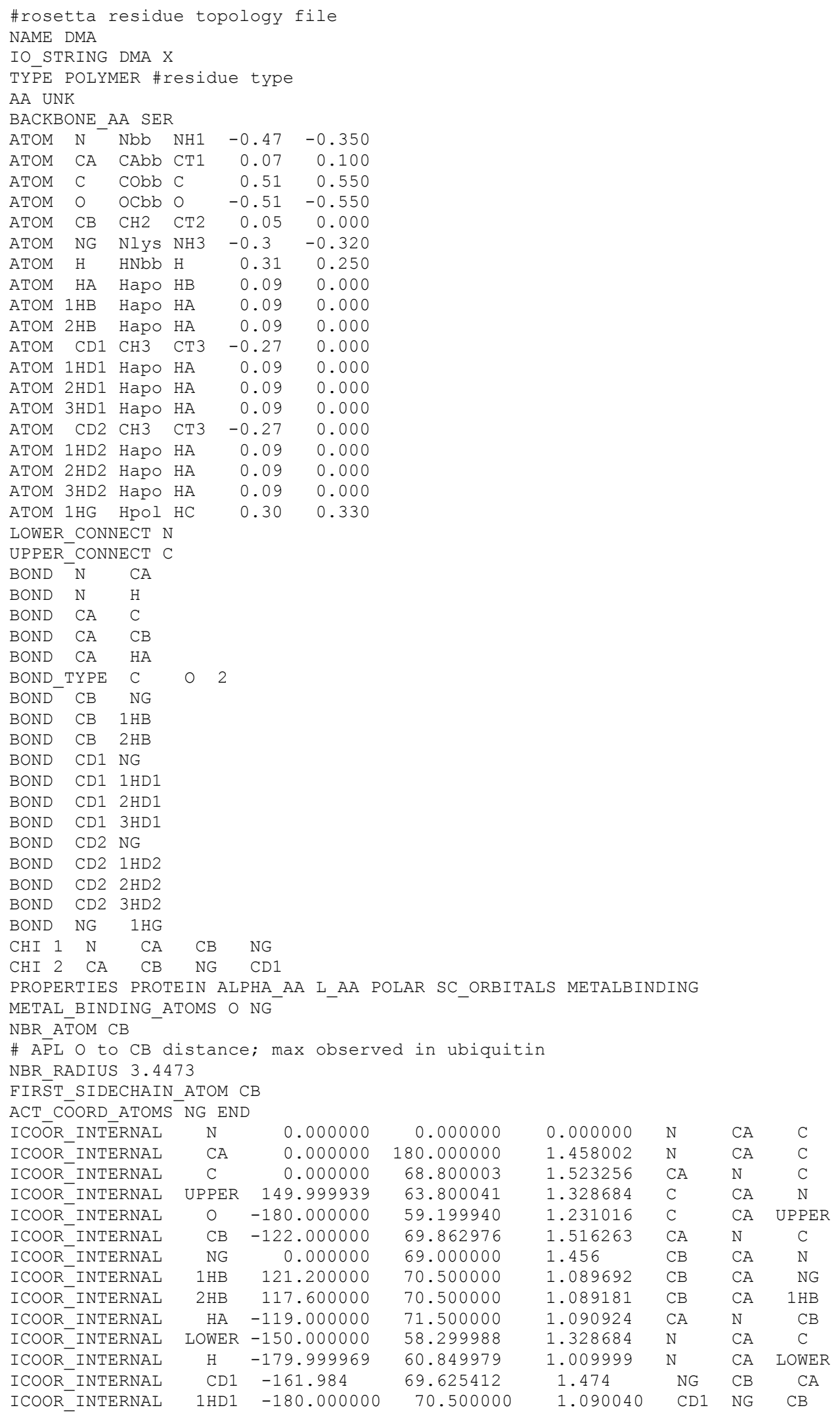


$\begin{array}{lrl}\text { ICOOR_INTERNAL } & \text { 2HD1 } & 120.000000 \\ \text { ICOOR_INTERNAL } & \text { 3HD1 } & 120.000000 \\ \text { ICOOR_INTERNAL } & \text { CD2 } & 76.310 \\ \text { ICOOR_INTERNAL } & \text { 1HD2 } & -180.000000 \\ \text { ICOOR_INTERNAL } & \text { 2HD2 } & 120.000000 \\ \text { ICOOR_INTERNAL } & \text { 3HD2 } & 120.000000 \\ \text { ICOOR_INTERNAL } & \text { 1HG } & -116.157 \\ \text { NCAA_ROTLIB_PATH } & \text { DMA.rot } 1 \text { IIb }\end{array}$

NCAA_ROTLIB_NUM_ROTAMER_BINS 236

\section{ii. Acpc Parameters File}

NAME ACP

IO STRING ACP $X$

TYPE POLYMER

AA UNK

ATOM N Nbb NH1 -0.60

ATOM CA CAbb CT1 -0.08

ATOM C CObb C 0.63

ATOM $O \quad$ OCbb $O \quad-0.54$

ATOM CB1 CH1 CT1 -0.08

AтOM CB2

$\begin{array}{lll}\text { ATOM H } & \text { HNbb } \mathrm{H} & 0.44\end{array}$

ATOM 1HB1 Hapo HA 0.10

ATOM 2HB1 Hapo HA 0.10

ATOM 1HB2 Hapo HA 0.10

ATOM 2HB2 Hapo HA 0.10

BOND N H

BOND N CA

BOND CB1 CA

BOND C CA

BOND CA CB2

BOND O C

BOND CB1 1HB1

BOND CB1 2HB1

BOND CB2 1HB2

BOND CB2 2HB2

BOND $\mathrm{CB} 1 \quad \mathrm{CB} 2$

LOWER_CONNECT N

UPPER_CONNECT C

NBR ATTOM CB1

NBR_RADIUS 6.991205

FIRST SIDECHAIN ATOM CB1

PROPERTIES PROTEIN ACHIRAL_BACKBONE

ICOOR INTERNAL N 0.000000

$\begin{array}{llll} & \text { CA } & 0.000000 & 180.000000\end{array}$

ICOOR_INTERNAL C $\quad 0.000000 \quad 63.227$

ICOOR INTERNAL LOWER -150.00003158 .300003$

ICOOR_INTERNAL UPPER $150.000015 \quad 63.800018$

ICOOR INTERNAL $\quad-180.000000 \quad 59.199963$

$\begin{array}{llll}\text { ICOOR_INTERNAL CB1 } & 145.250 & 61.252783\end{array}$

ICOOR INTERNAL

ICOOR INTERNAL

ICOOR INTERNAL

ICOOR_INTERNAI

CB2 -145.250

$1 \mathrm{HB} 2 \quad 0.0$

2HB2 143.929

1HB1 -143.929

2HB1 143.929

ICOOR_INTERNAL
500000

500000

70.500000

70.500000

.500000

2.584

$\begin{array}{lrrr}1.090069 & \mathrm{CD} 1 & \mathrm{NG} & 1 \mathrm{HD} 1 \\ 1.088803 & \mathrm{CD} 1 & \mathrm{NG} & 2 \mathrm{HD} 1 \\ 1.474 & \mathrm{NG} & \mathrm{CB} & \mathrm{CA} \\ 1.090040 & \mathrm{CD} 2 & \mathrm{NG} & \mathrm{CB} \\ 1.090069 & \mathrm{CD} 2 & \mathrm{NG} & 1 \mathrm{HD} 2 \\ 1.088803 & \mathrm{CD} 2 & \mathrm{NG} & 2 \mathrm{HD} 2 \\ 1.000 & \mathrm{NG} & \mathrm{CD} 1 & \mathrm{CB}\end{array}$

1.090069 CD1 NG 1HD1

1.088803 CD1 NG 2HD1

$1.090040 \quad \mathrm{CD} 2 \quad \mathrm{NG} \quad \mathrm{CB}$

1.088803 CD2 NG 2HD2 


\section{B. Conformational Sampling Analysis}

The conformational sampling analysis was performed following the procedure reported by Hosseinzadeh, Bhardwaj, Mulligan, et al. ${ }^{3}$ In brief, simple_cycpep_predict app in Rosetta was employed to generate tens of thousands of closed solutions for each peptide. The solutions were analyzed by plotting their Rosetta score versus their root mean square deviation from the designed models. The score function was modified to mimic the organic conditions by turning off the solvation term and increasing the hydrogen bonding weights.

The command prompt to run the analysis is as follows:

<Path-To-Rosetta-bin>/simple_cycpep_predict.default.linuxgccrelease @rosetta.flags

The flags are shown below:

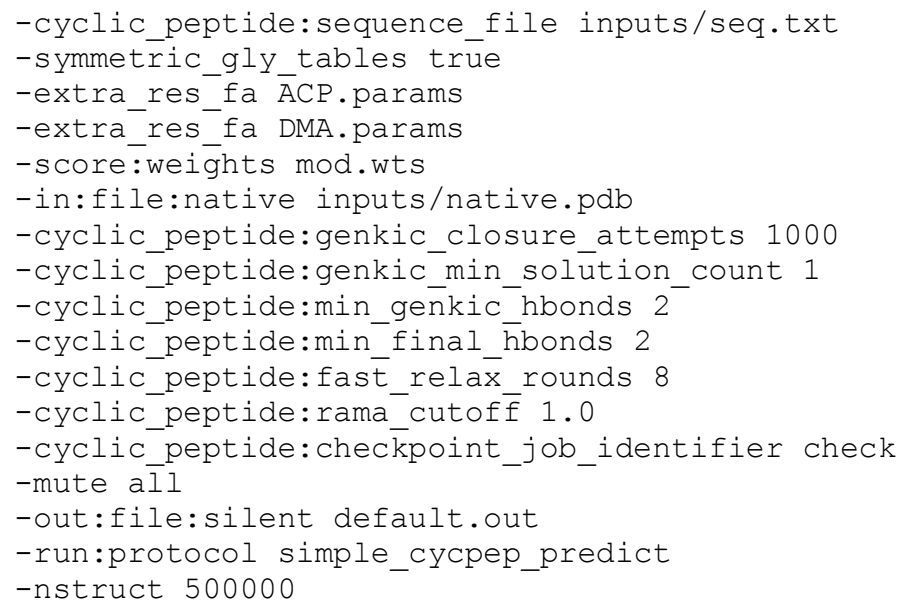

mod.wts file

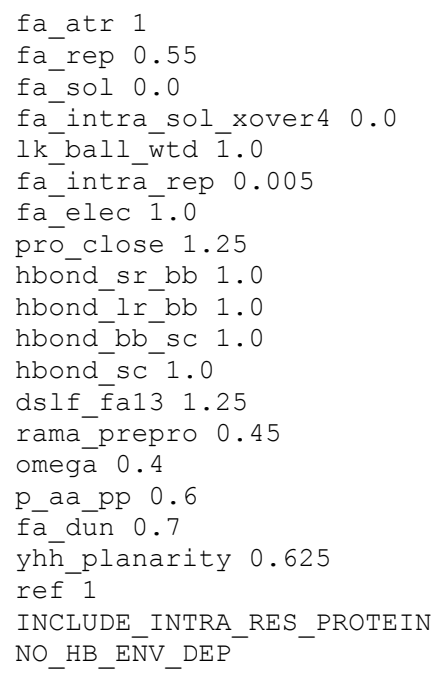




\section{Designs Using Pre-Existing Scaffolds}

The search for the desired turn was performed using previously reported motif-analysis method. ${ }^{3}$ After matching, the catalytic residues were placed in the corresponding locations using MutateResidue mover in Rosetta. The rest of the peptide was then designed with FastDesign ${ }^{8}$ mover using design.xml script shown below. Only hydrophobic residues were allowed to be used due to the reaction conditions. In addition, to facilitate the downstream spectroscopy-based analysis, one phenylalanine (D or L) was required for each design. The command to run the design is as follows:

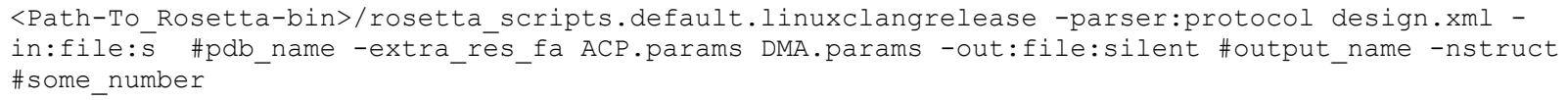

\section{Design.xml file:}

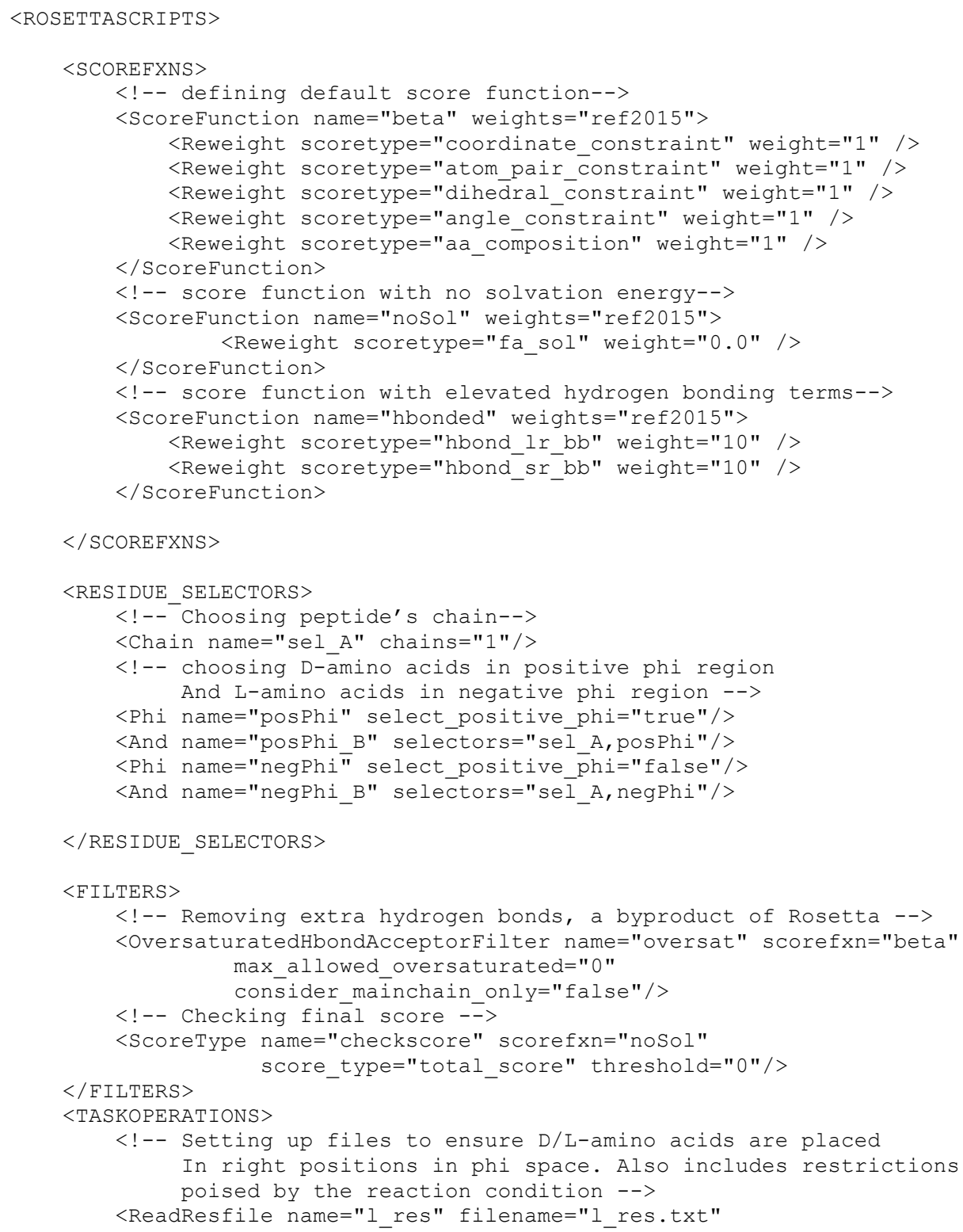




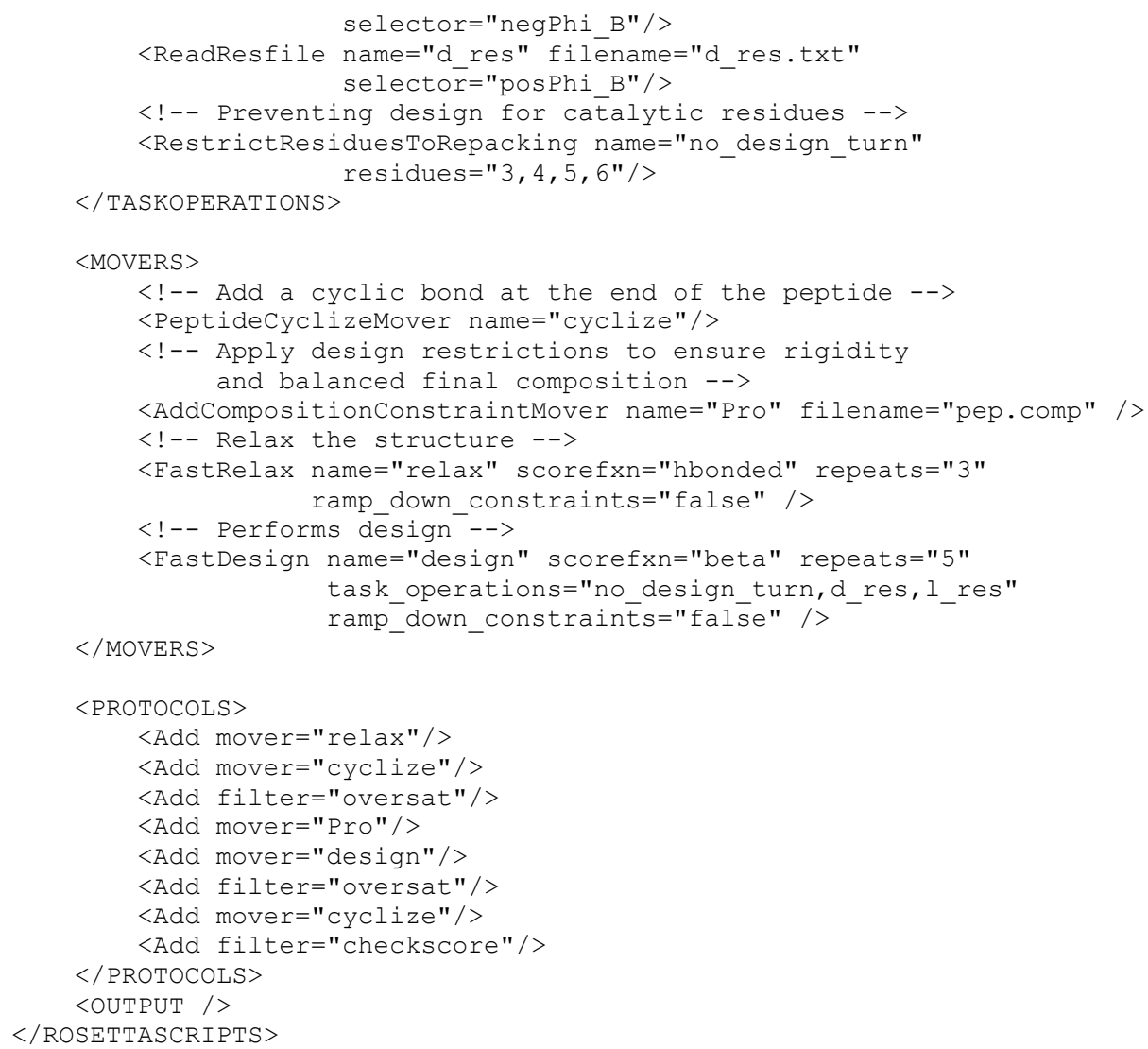

\section{Resfiles used in the design.xml script:}

1 res.txt

RESET

PIKAA LVFAPI

start

\section{$\underline{\mathrm{d} \text { res.txt }}$}

EMPTY NC DAL NC DPH NC DIL NC DLE NC DVA NC DPR

start

\section{pep.comp composition file}

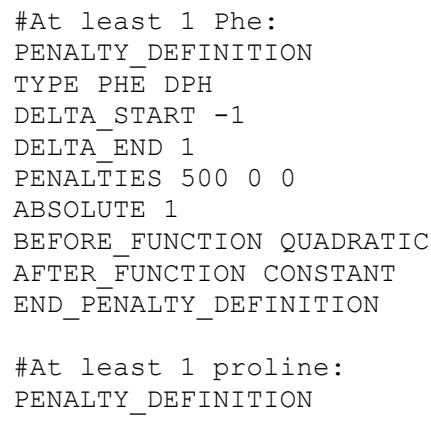


TYPE PRO DPR

DELTA_START - 1

DELTA END 1

PENALTIES $100 \quad 0 \quad 0$

ABSOLUTE 1

BEFORE FUNCTION QUADRATIC

AFTER FUNCTION CONSTANT

END_PENALTY_DEFINITION

\#At most 1 alanine:

PENALTY DEFINITION

TYPE ALA DAL

DELTA START -1

DELTA_END 2

PENALTIES 00050100

ABSOLUTE 1

BEFORE FUNCTION CONSTANT

AFTER_FUNCTION QUADRATIC

END PENALTY DEFINITION

\section{Designs Starting from Tetrapeptide 3}

Backbones that could accommodate the original tetrapeptide were generated using the python script below that performs fast peptide backbone generation by wrapping the generalized kinematic loop closure mover in Rosetta. ${ }^{8}$ The generated peptides were designed using a design protocol similar to above, with lines for mutation being removed. The backbones generated with this method then were designed using the same design script described above.

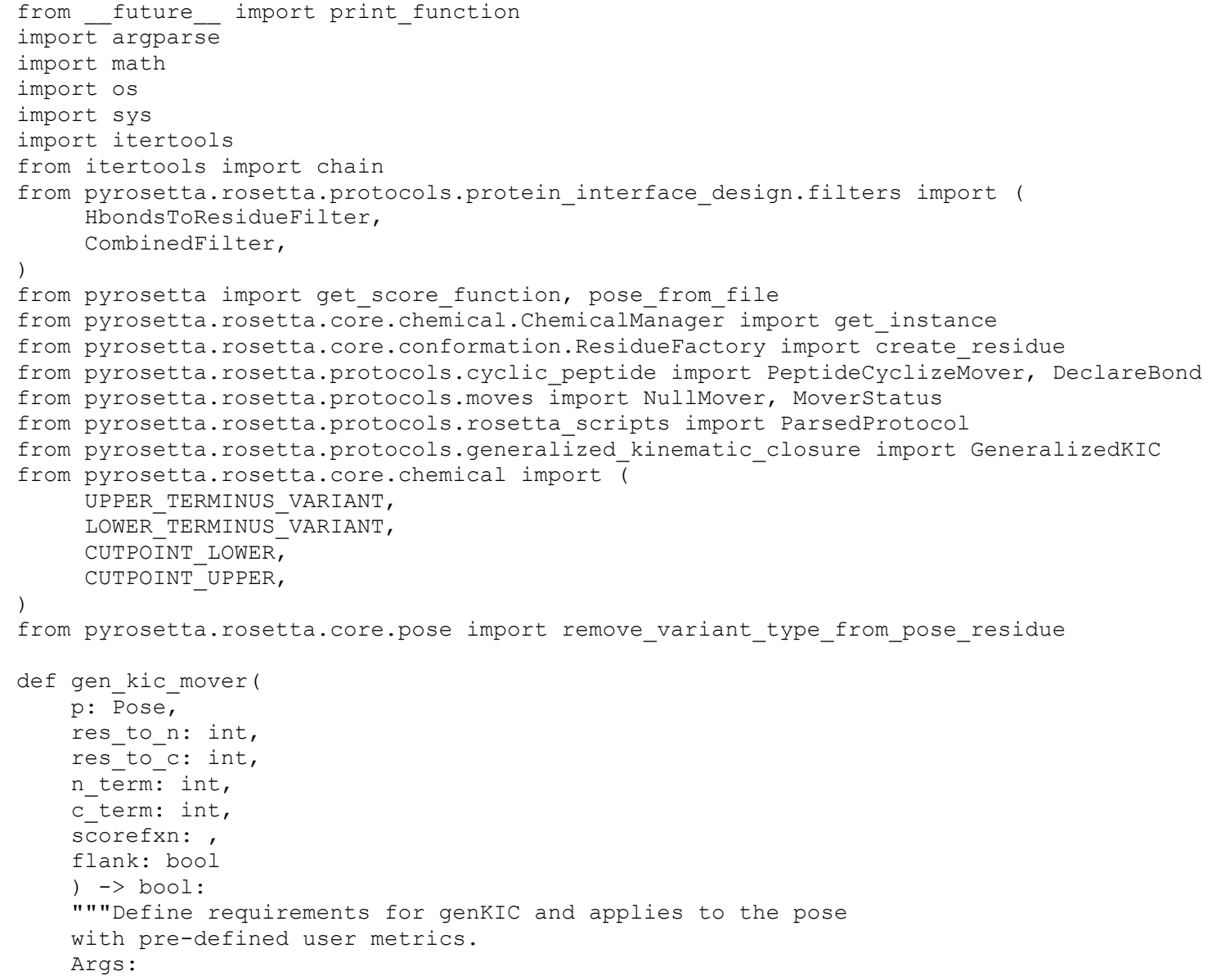




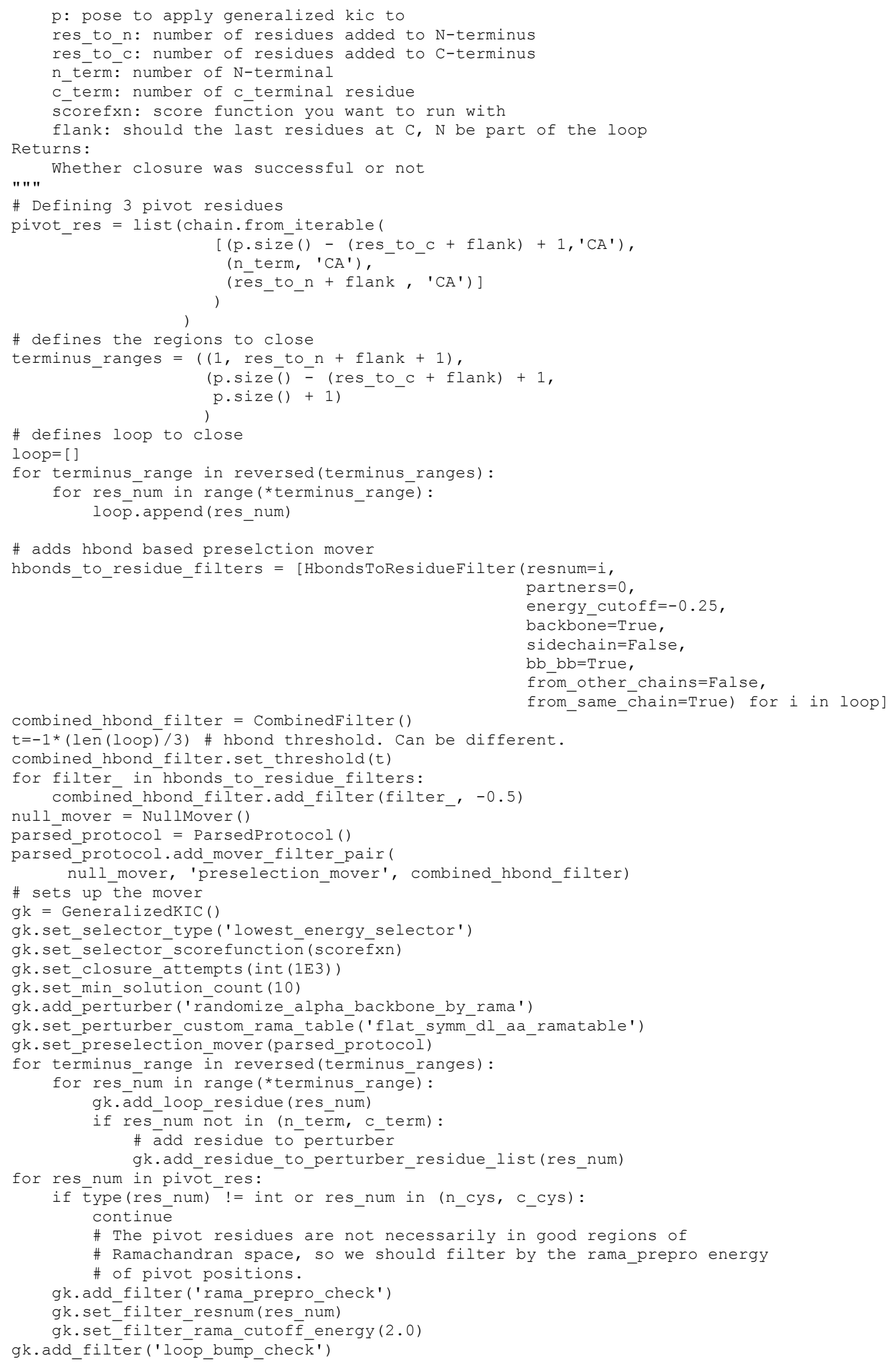




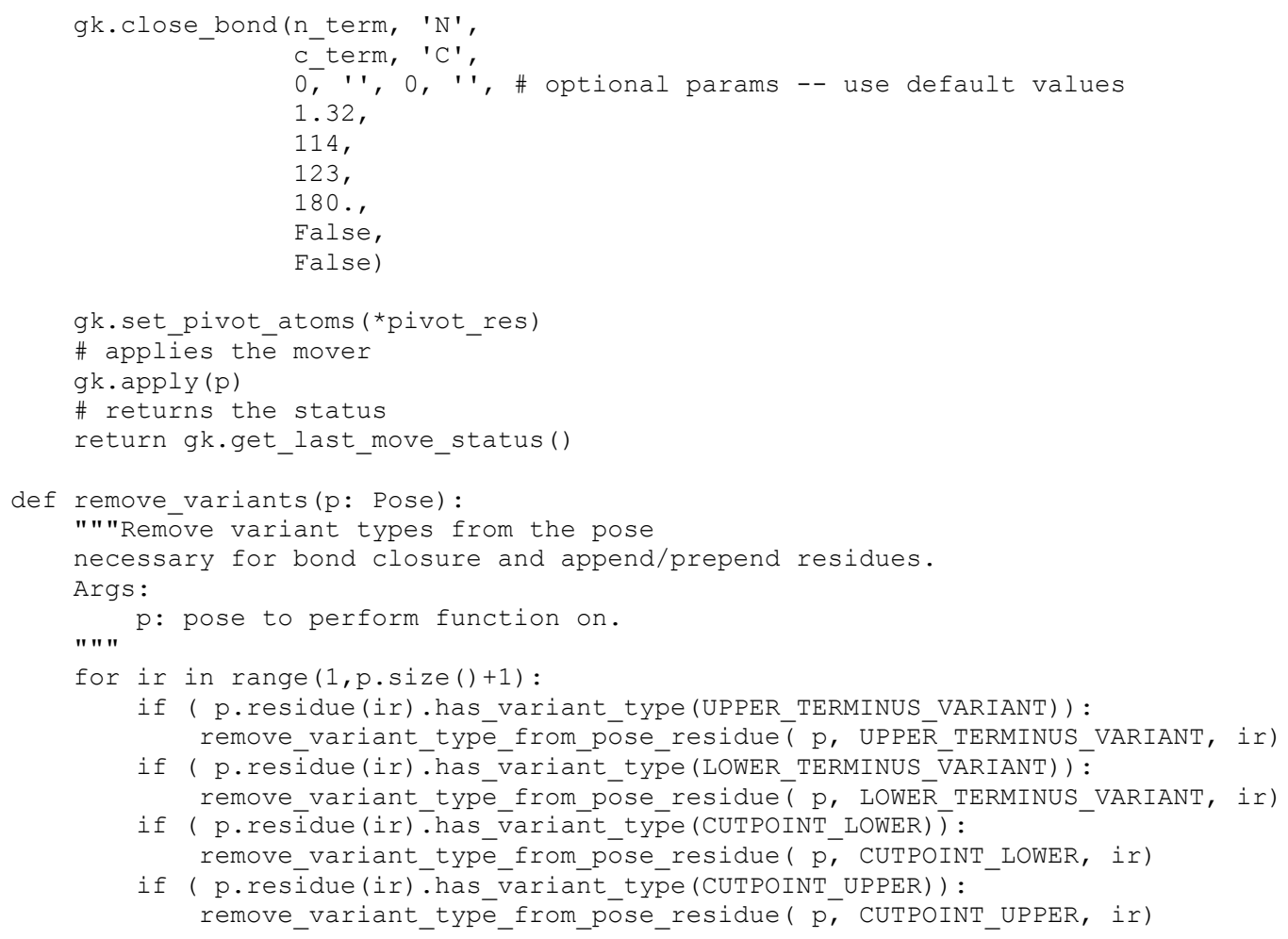

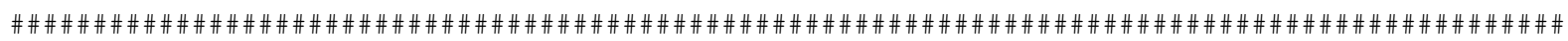
\#\#\#\#\#\#\#\#\#\#\#\#\#\#\#\#\#\#\#\#\#\#\#\#\#\# MAIN GUNCTION THAT CALLS EVERYTHING ELSE \#\#\#\#\#\#\#\#\#\#\#\#\#\#\#\#\#\#\#\#\#\#\#\#

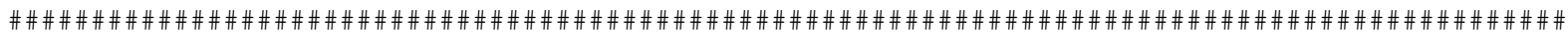
def main(argv):

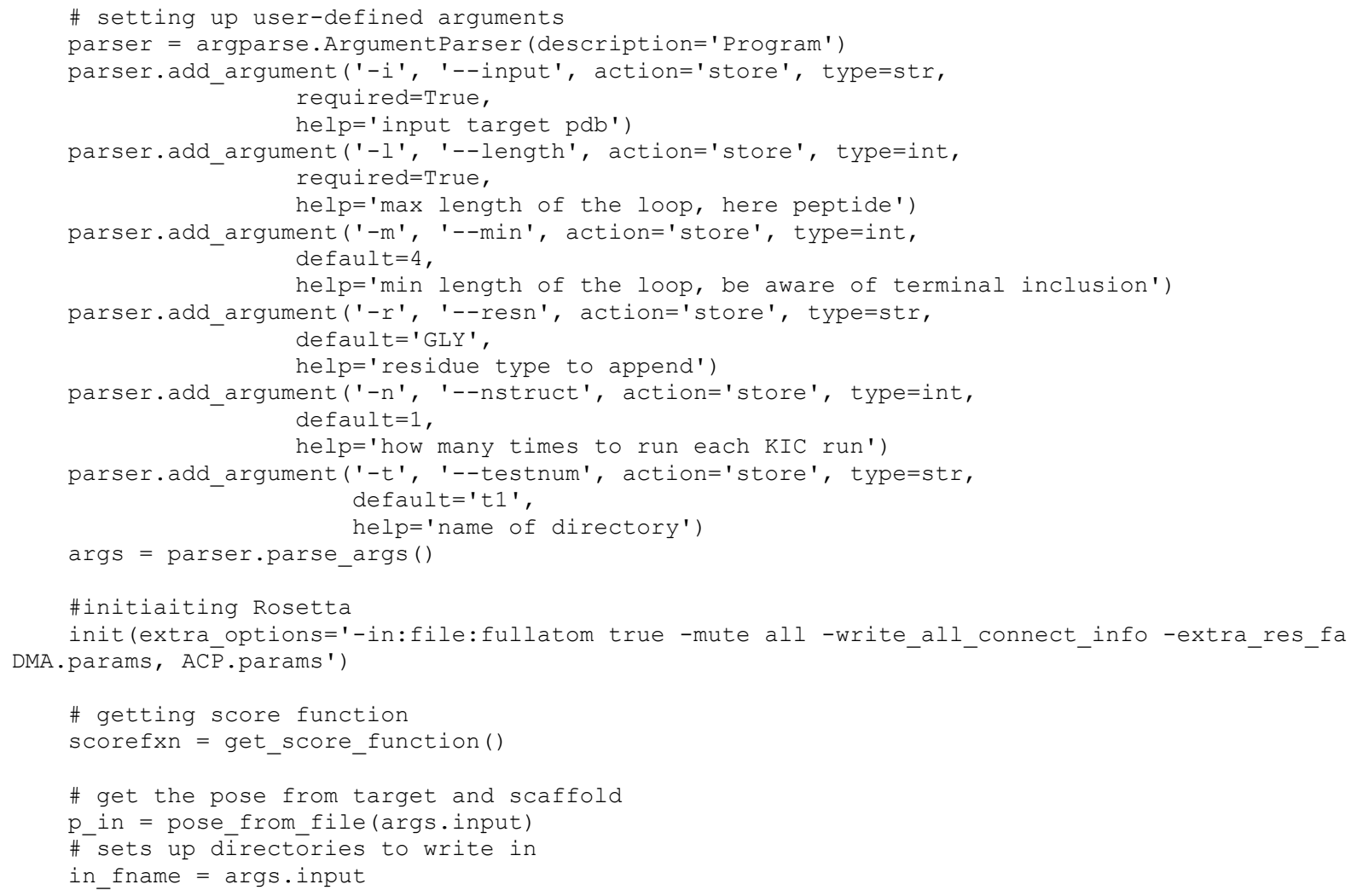




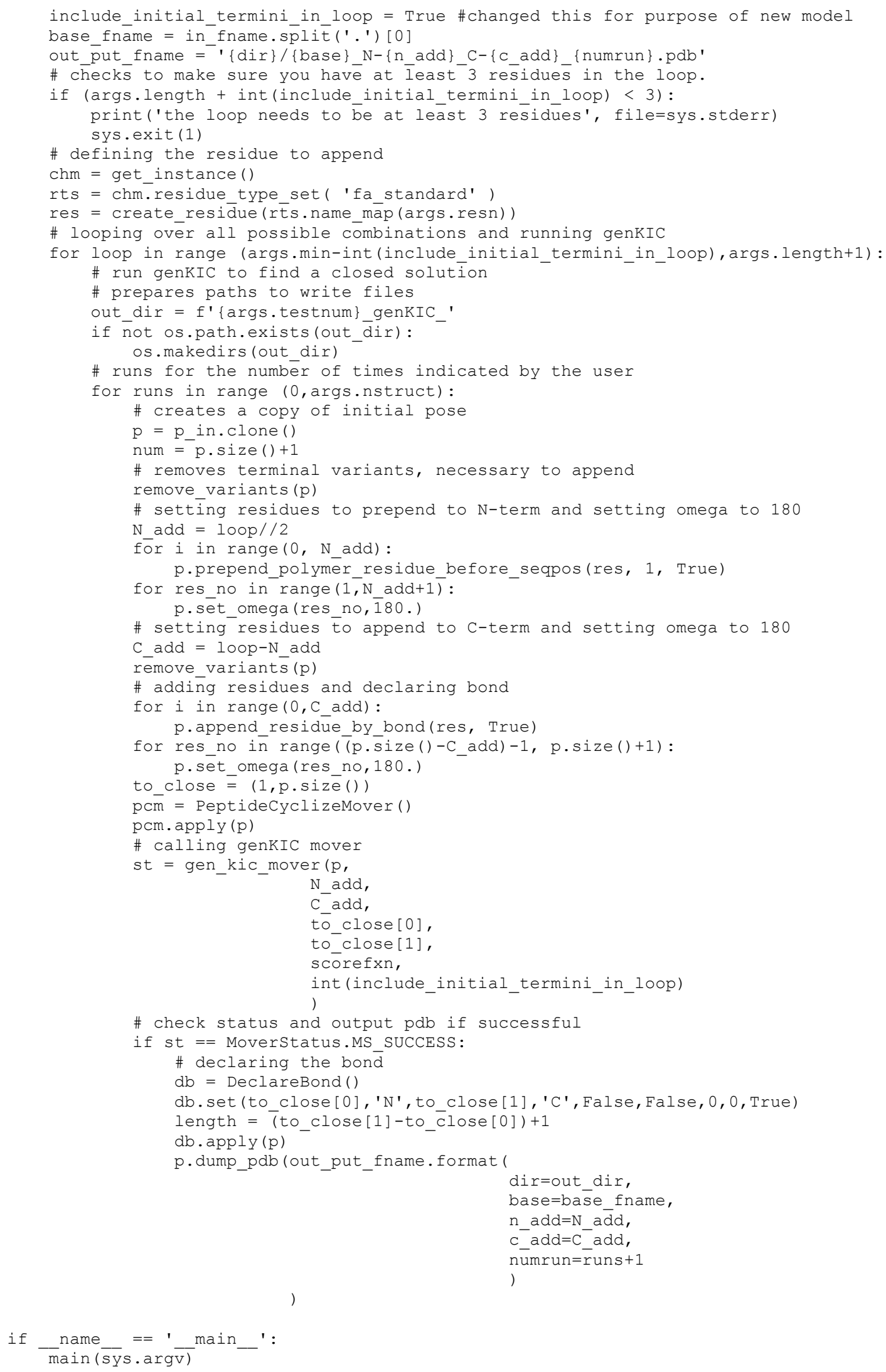




\section{E. Molecular Dynamics Simulations}

All simulations were prepared starting from the designs generated by Rosetta. $\mathrm{VMD}^{9}$ was used to solvate the peptides in a cubic box of benzene roughly $33 \AA$ wide. The system was then prepared for simulation with the OPLS-AA ${ }^{10} / \mathrm{CM} 1 \mathrm{~A}$ force field for the ligand and the OPLS-AA/ $\mathrm{M}^{11}$ force field for the peptide, using the unnatural amino acid parameters derived previously. Simulations were run in $\mathrm{NAMD}^{12}$ at $300 \mathrm{~K}$ enforced with a Langevin thermostat with a dampening coefficient of $1 \mathrm{ps}^{-1}$ and at a pressure of $1 \mathrm{~atm}$ enforced with a Nose-Hoover Langevin piston barostat with a period of $100 \mathrm{fs}$ and a decay of $50 \mathrm{fs}$. The system was minimized for 1500 steps before gradual heating from $0 \mathrm{~K}$ to $300 \mathrm{~K}$ in $0.4 \mathrm{~ns}$ long-increments of $20 \mathrm{~K}$. Harmonic restraints were applied to the peptide and ligand non-hydrogen atoms during the minimization and heating phases at a strength of $1 \mathrm{kcal} / \mathrm{mol} / \mathrm{A}^{2}$. Periodic boundary conditions were enforced and nonbonded interactions were smoothed starting at $10 \AA$ and ending at $12 \AA$ with particle mesh Ewald used for long-range effects.
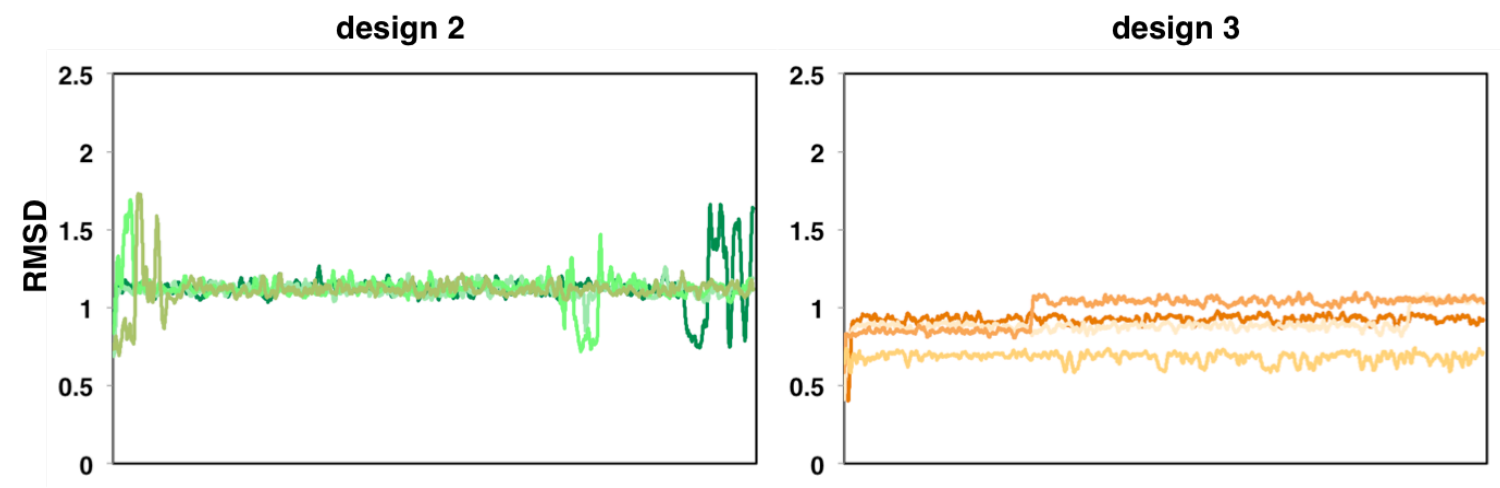

Figure S1. Representative MD trajectories of designs 2 and design 3 without substrate.

\section{References}

1. Metrano, A. J.; Miller, S. J. Peptide-Catalyzed Conversion of Racemic Oxazol-5(4H)-ones into Enantiomerically Enriched a-Amino Acid Derivatives. J. Org. Chem. 2014, 79, 1542-1554.

2. Metrano, A. J.; Abascal, N. C.; Mercado, B. Q.; Paulson, E. K.; Miller, S. J. Structural Studies of $\beta$-turnContaining Peptide Catalysts for Atroposelective Quinazolinone bBomination. Chem. Commun. 2016, 52, 4816-4819.

3. Hosseinzadeh, P.; Bhardwaj, G.; Mulligan, V. K.; Shortridge, M. D.; Craven, T. W.; Pardo-Avila, F.; Rettie, S. A.; Kim, D. E.; Silva, D.-A.; Ibrahim, Y. M.; Webb, I. K.; Cort, J. R.; Adkins, J. N.; Varani, G.; Baker, D. Comprehensive Computational Design of Ordered Peptide Macrocycles. Science 2017, 358, 1461-1466.

4. Diener, M. E.; Metrano, A. J.; Kusano, S.; Miller, S. J. Enantioselective Synthesis of 3-Arylquinazolin4(3H)-ones via Peptide-Catalyzed Atroposelective Bromination. J. Am. Chem. Soc. 2015, 137, 1236912377. 
5. Drew, K.; Renfrew, P. D.; Craven, T. W.; Butterfoss, G. L.; Chou, F.-C.; Lyskov, S.; Bullock, B. N.; Watkins, A.; Labonte, J. W.; Pacella, M.; Kilambi, K. P.; Leaver-Fay, A.; Kuhlman, B.; Gray, J. J.; Bradley, P.; Kirshenbaum, K.; Arora, P. S.; Das, R.; Bonneau, R. Adding Diverse Noncanonical Backbones to Rosetta: Enabling Peptidomimetic Design. PLOS ONE 2013, 8, e67051.

6. Renfrew, P. D.; Craven, T. W.; Butterfoss, G. L.; Kirshenbaum, K.; Bonneau, R. A Rotamer Library to Enable Modeling and Design of Peptoid Foldamers. J. Am. Chem. Soc. 2014, 136, 8772-8782.

7. Mulligan, V. K.; Kang, C. S.; Sawaya, M. R.; Rettie, S.; Li, X.; Antselovich, I.; Craven, T. W.; Watkins, A. M.; Labonte, J. W.; DiMaio, F.; Yeates, T. O.; Baker, D. Computational Design of Mixed Chirality Peptide Macrocycles with Internal Symmetry. Protein Sci. 2020, 29, 2433-2445.

8. Bhardwaj, G.; Mulligan, V. K.; Bahl, C. D.; Gilmore, J. M.; Harvey, P. J.; Cheneval, O.; Buchko, G. W.; Pulavarti, S. V. S. R. K.; Kaas, Q.; Eletsky, A.; Huang, P.-S.; Johnsen, W. A.; Greisen, P., Jr.; Rocklin, G. J.; Song, Y.; Linsky, T. W.; Watkins, A.; Rettie, S. A.; Xu, X.; Carter, L. P.; Bonneau, R.; Olson, J. M.; Coutsias,

E.; Correnti, C. E.; Szyperski, T.; Craik, D. J.; Baker, D. Accurate de novo Design of Hyperstable Constrained Peptides. Nature 2016, 538, 329-335.

9. Humphrey, W.; Dalke, A.; Schulten, K. VMD: Visual Molecular Dynamics. J. Mol. Graph. 1996, 14, 33-38.

10. Jorgensen, W. L.; Maxwell, D. S.; Tirado-Rives, J. Development and Testing of the OPLS All-Atom Force Field on Conformational Energetics and Properties of Organic Liquids. J. Am. Chem. Soc. 1996, $118,11225-11236$.

11. Robertson, M. J.; Tirado-Rives, J.; Jorgensen, W. L. Improved Peptide and Protein Torsional Energetics with the OPLS-AA Force Field.J. Chem. Theory Comput. 2015, 11, 3499-3509.

12. Phillips, J. C.; Braun, R.; Wang, W.; Gumbart, J.; Tajkhorshid, E.; Villa, E.; Chipot, C.; Skeel, R. D.; Kalé, L.; Schulten, K. Scalable Molecular Dynamics with NAMD. J. Comp. Chem. 2005, 26, 1781-1802. 